Prepared in cooperation with the North Carolina Department of Transportation

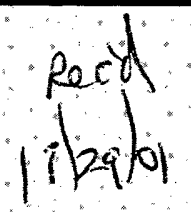

\title{
Estimating the Magnitude and Frequency of Floods in Rural Basins of North Carolina-Revised
}

U.S Geological Survey

Water-Resources Investigations Report 01-4207.

(Suprsedes wriR $99-4114)_{\mathrm{Mab}}$ 


\section{Estimating the Magnitude and Frequency of Floods in Rural Basins of North Carolina-Revised}

By Benjamin F. Pope, Gary D. Tasker, and Jeanne C. Robbins

U.S. GEOLOGICAL SURVEY

Water-Resources Investigations Report 01-4207

Prepared in cooperation with the

North Carolina Department of Transportation

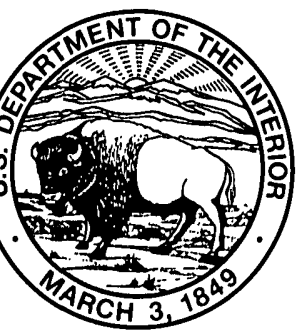




\title{
U.S. DEPARTMENT OF THE INTERIOR \\ GALE A. NORTON, Secretary
}

\author{
U.S. GEOLOGICAL SURVEY
}

CHARLES G. GROAT, Director

The use of firm, trade, and brand names in this report is for identification purposes only and does not constitute endorsement by the U.S. Geological Survey.

For additional information write to:

Copies of this report can be purchased from:

District Chief

U.S. Geological Survey 3916 Sunset Ridge Road

Raleigh, NC 27607

Email:dc_nc@usgs.gov
U.S. Geological Survey

Branch of Information Services

Box 25286, Federal Center

Denver, CO 80225

1-888-ASK-USGS

Information about U.S. Geological Survey programs in North Carolina can be obtained on the Internet at http://nc.water.usgs.gov. 


\section{PREFACE}

This report revises and supersedes U.S. Geological Survey Water-Resources Investigations Report 99-4114. The revised flood-discharge values are listed in table 2 (Q2, Q5, Q10, Q25, Q50, Q100, Q200, and Q500). The revised flood discharges, for all recurrence intervals, vary by as much as 17 percent from the earlier published values, with 80 percent of all values within 7 percent of the earlier published data. Differences in the values for the 100-, 200-, and 500 -year discharges are greater than in the values for the 2-, 5-, 10-, 25-, and 50-year discharges, 80 percent of which are within 3 percent of the earlier published values.

The revised $t$-year discharges were used to update the regional regression equations and the region-of-influence data base, as indicated in revised text tables 5, 6, and 7 and in appendix table 1. The maximum difference in computed results for the regional regression equations was noted for the Coastal Plain equations, where application of the revised equations to small drainage areas, less than 10 square miles, resulted in discharges that are about 3 to 9 percent greater than those values obtained using equations from the previous report. Computed flood discharges using the revised Blue Ridge-Piedmont equations generally were within about 2 percent of the values from the previously published equations, except for results for drainage areas less than 10 square miles, which ranged from about 3 to 7 percent less than the previously published values. Application of the revised regression equations to the Sand Hills hydrologic area shows results in discharges that are up to 3 percent less than those computed using the equations published in the earlier report. The average error of prediction for the revised equations was nearly the same as for the earlier published Blue Ridge-Piedmont equations, lower for the Coastal Plain equations, and higher for the Sand Hills equations.

As in the previous report, the root mean square error (RMSE) for the region-of-influence method was only marginally better than the RMSE reported for the regional regression equations, resulting in neither method being clearly superior. The revised computer program for computing the estimates of floodfrequency discharges, using either the regional regression equations or the region-of-influence method, and the associated site-specific errors of prediction are available at the North Carolina District Web site http://nc.water.usgs.gov/reports/ wri014207. 


\section{CONTENTS}

Preface

Abstract

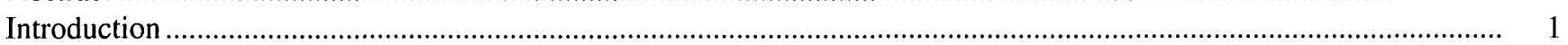

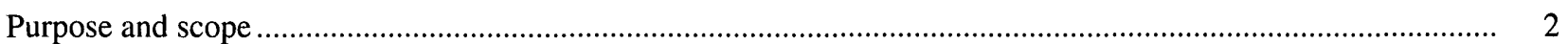

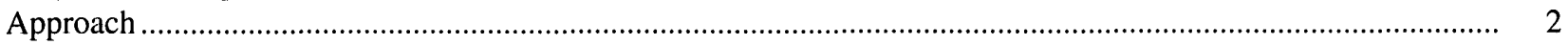

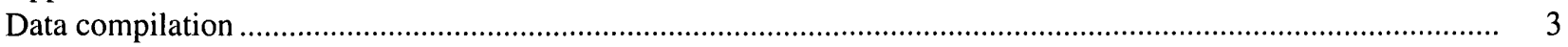

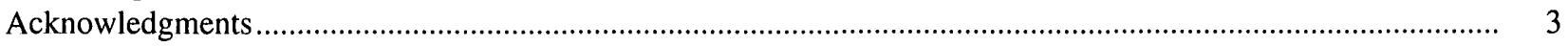

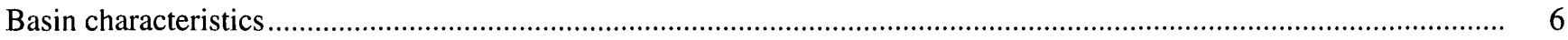

Estimation of flood magnitude and frequency at gaged sites ................................................................................ 7

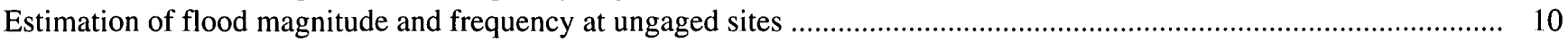

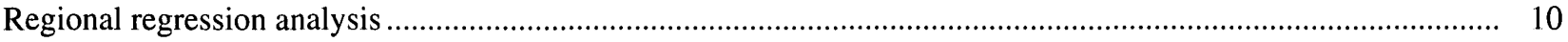

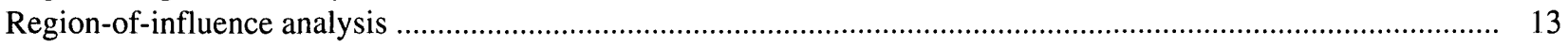

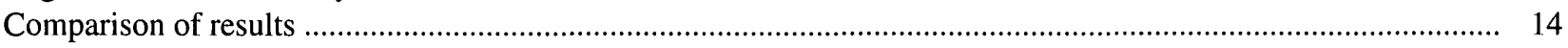

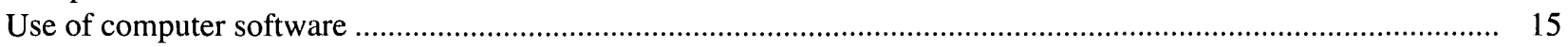

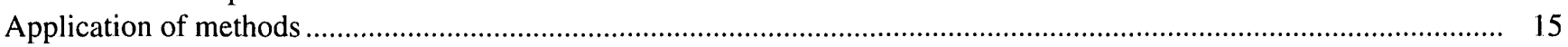

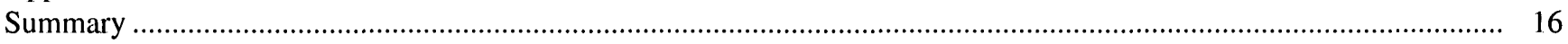

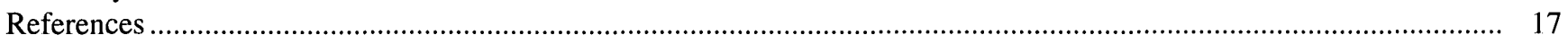

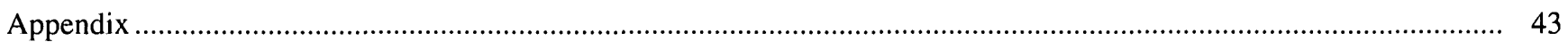

FIGURES

1. Locations of gaged rural sites in North Carolina ...................................................................................... 4

\section{TABLES}

1. Map identification numbers and descriptions of gaged rural sites in North Carolina with annual peak-flow record

2. Recurrence interval discharges and basin characteristics for gaged rural sites in North Carolina

3. Basin characteristics that were used in the North Carolina flood-frequency regionalization study

4. Generalized skew coefficient and associated mean square error for rural

North Carolina gaging sites

5. North Carolina rural flood-frequency equations

6. Average predictive errors and equivalent years of record associated with North Carolina rural flood-frequency equations

7. Root mean square error for the regional regression and region-of-influence methods, presented by hydrologic area and recurrence interval 


\section{CONVERSION FACTORS and ABBREVIATIONS/ACRONYMS}

\begin{tabular}{lcll}
\hline Multiply & By & To obtain \\
\hline \multirow{3}{*}{ mile (mi) } & Length & \\
& 1.609 & kilometer \\
& Area &
\end{tabular}

\begin{tabular}{rcl} 
square mile $\left(\mathrm{mi}^{2}\right)$ & 2.590 & square kilometer \\
& Flow & \\
foot per mile $(\mathrm{ft} / \mathrm{mi})$ & 0.1894 & meter per kilometer \\
cubic foot per second $\left(\mathrm{ft}^{3} / \mathrm{s}\right)$ & 0.02832 & cubic meter per second \\
\hline
\end{tabular}

\section{Abbreviations/Acronyms:}

BRP

Blue Ridge-Piedmont hydrologic area

BSLOPE

basin slope

$\mathrm{CP}$

Coastal Plain hydrologic area

CSLOPE

channel slope

DA

drainage area

DEM

digital elevation model

GIS

geographic information system

L

channel length

REG region variable

RMSE root mean square error

SH Sand Hills hydrologic area

SHAPE basin shape

USGS U.S. Geological Survey 


\title{
Estimating the Magnitude and Frequency of Floods in Rural Basins of North Carolina-Revised
}

\author{
By Benjamin F. Pope, Gary D. Tasker, and Jeanne C. Robbins
}

\section{ABSTRACT}

A statewide study was conducted to develop two methods for estimating the magnitude and frequency of floods in rural ungaged basins in North Carolina. Flood-frequency estimates for gaged sites in North Carolina were computed by fitting the annual peak flows for each site to a logPearson Type III distribution. As part of the computation of flood-frequency estimates for gaged sites, new values for generalized skew coefficients were developed. Basin characteristics for these gaged sites were computed by using a geographic information system and automated computer algorithms. Flood-frequency estimates and basin characteristics for 317 gaged sites were combined to form the data base that was used for this analysis.

Regional regression analysis, using generalized least-squares regression, was used to develop a set of predictive equations that can be used to estimate the 2-, 5-, 10-, 25-, 50-, 100-, 200-, and 500-year recurrence interval discharges for rural ungaged basins in the Blue RidgePiedmont, Coastal Plain, and Sand Hills hydrologic areas. The predictive equations are all functions of drainage area. Average errors of prediction for these regression equations range from 36 to 65 percent.

A region-of-influence method also was developed that interactively estimates recurrence interval discharges for rural ungaged basins in the Blue Ridge-Piedmont and Coastal Plain hydrologic areas of North Carolina. Regression techniques are used to develop a unique relation between flood discharge and basin characteristics for a subset of gaged sites with similar basin characteristics. This, then, can be used to estimate flood discharges at ungaged sites. Because the computations required for this method are somewhat complex, a computer application was developed that performs the computations and compares the predictive errors for this method. The computer application also includes the option of using the regression equations to compute estimated flood discharges and errors of prediction specific to each ungaged site.

Root mean square errors, computed for each recurrence interval and hydrologic area, are generally only slightly lower for the region-ofinfluence method than for the regression equations and do not provide sufficient basis for recommending one method over the other. In addition, the region-of-influence method is a new method that is still being improved. As a result, the regional regression equations are considered to be the primary method for computing floodfrequency estimates at ungaged sites.

\section{INTRODUCTION}

Reliable estimates of the magnitude and frequency of floods are needed by State and local designers and managers. The design of highway and railroad stream crossings, delineation of flood plains and flood-prone areas, management of water-control structures, and management of water supplies are all activities that require estimates of the frequency distribution of flood events. Such estimates can be computed directly by using statistical methods at gaged 
sites that have at least 10 years of annual peak record; the longer the record of annual peak flows, the more reliable the estimate. It is not feasible, however, to collect 10 years of annual peak record for every location where an estimate of the flood-frequency distribution is needed, nor is it reasonable to wait 10 years for an estimate once a site has been identified.

Estimates that are derived solely from gage records do not provide sufficient spatial coverage to satisfy the need for reliable estimates of the magnitude and frequency of floods. Traditionally, to meet this need, annual peak records at gaged sites have been regionalized, or extended in space. By this process, flood-frequency estimates at gaged sites are related to measurable basin characteristics so that reliable floodfrequency estimates can be made at ungaged sites. In response to the need to improve the accuracy of estimates of flood discharges for ungaged rural basins, the U.S. Geological Survey (USGS), in cooperation with the North Carolina Department of Transportation, initiated an investigation in 1996 to further define the relation between flood discharges of selected recurrence intervals and selected basin characteristics for rural North Carolina basins.

In the past, regionalization was achieved by means of regional regression analysis. Data from gaged sites were used to define a set of relations between selected recurrence interval discharges and drainage area. Once defined, these relations were then used to estimate discharges at selected recurrence intervals for ungaged sites. Often the area of study was subdivided into regions of similar hydrology in order to improve the predictive ability of the equations. Gunter and others (1987) used this approach to develop regional relations for estimating the magnitude and frequency of floods in rural North Carolina basins.

Recently, however, a different approach to regionalization has been developed. This new approach, known as the region-of-influence method, interactively estimates recurrence interval discharges for ungaged sites based on data from gaged sites with similar basin characteristics. For each ungaged site selected, a subset of gaged sites having similar basin characteristics is selected from the entire data base of rural gaged sites. Regression techniques are used to develop a unique relation between flood discharge and basin characteristics for this subset of gaged sites. This relation is then used to estimate flood discharges at the ungaged site. Although computationally intensive, the region-of-influence method is easily automated and performed by a computer application that is discussed later in this report. Because only gaged sites with similar basin characteristics are used to estimate flows at ungaged sites, there is less chance of extrapolation beyond the limits of the explanatory data. Tests of this approach in Texas (Tasker and Slade, 1994) and in Arkansas (Hodge and Tasker, 1995) yielded estimates with lower prediction errors than those produced by using traditional regional regression techniques. Gunter and others (1987) contains annual peak-flow data collected from gages throughout North Carolina through the 1984 water year ${ }^{1}$, whereas this report contains peak-flow data collected through the 1996 water year. Thus, gaged sites that have continued in operation since 1984 have as much as 12 additional years of peak-flow data available for computation of flood-frequency estimates. The 12 intervening years (1985-96) include several years of pronounced drought (1985-88) as well as years in which maximum peaks of record were recorded (1992-93, 1996) for North Carolina streams. In addition, 64 gaged sites that were not used in Gunter and others (1987) are now available for analysis.

\section{Purpose and Scope}

This report describes the development, application, and evaluation of two methods for estimating the magnitude and frequency of floods at ungaged, unregulated, rural basins in North Carolina-(1) the regional regression method and (2) the region-of-influence method. A comparison of these two methods, based on their predictive ability and ease of application, also is presented. In order to compare the two methods on an equal basis, each method was applied to the same available data. The regional regression and region-of-influence methods of estimation were applied to the current data base of 317 sites with at least 10 years of unregulated peak-flow record and evaluated.

\section{Approach}

A set of eight basin characteristics was computed and compiled for each of 366 gaged rural sites in North Carolina that have peak-flow record. Sites that have

\footnotetext{
${ }^{1}$ Water year is the period October 1 through September 30 and is identified by the year in which it ends.
} 
flows affected by regulation or channelization were identified, and where possible, records for such sites were divided into periods of unregulated and regulated flows. Weighted regional average skew values were used to compute flood-frequency estimates for 317 sites with at least 10 years of unregulated peak-flow record. Flood-frequency estimates and the computed basin characteristics for these 317 sites were combined to form the data base used in the regional analyses.

Generalized least-squares regression analysis was used to develop predictive equations relating the 2-, 5-, 10-, 25-, 50-, 100-, 200-, and 500-year recurrence interval flood discharges to selected basin characteristics for rural basins throughout North Carolina. In addition, a region-of-influence method was developed that interactively estimates the recurrence interval flood discharges for ungaged rural basins in the Blue Ridge-Piedmont and Coastal Plain hydrologic areas.

Computation and compilation of basin characteristics and of the selected recurrence interval discharges are described in the following sections. All aspects of each analysis, including the initial exploratory multiple regression analysis using ordinary least-squares regression, final regional regression using generalized least-squares regression, and the region-of-influence analysis, are described. Finally, a comparison of the results of each method is presented.

\section{Data Compilation}

The first step in the regionalization of floodfrequency estimates is the compilation of a list of all gaged sites with annual peak-flow record. Such sites are either continuous-record sites or crest-stage sites. At continuous-record sites, the water-surface elevation, or stage, of the stream is recorded at fixed intervals, typically ranging from 5 to 60 minutes. At crest-stage sites, only the crest, or highest, stages that occur between site visits, usually 6 to 8 weeks, are recorded. Regardless of the type of gage, measurements of discharge are determined throughout the range of recorded stages, and a relation between stage and discharge is developed for the gaged site. Using this stage-discharge relation, or rating, discharges for all recorded stages are determined. The highest peak discharge that occurs during a given year is the annual peak for the year, and the list of annual peaks is the annual peak-flow record. The three hydrologic areas identified and described by Gunter and others (1987), consisting of (1) the combined Blue Ridge and Piedmont physiographic provinces, (2) the Coastal Plain Province, and (3) a subdivision of the Coastal Plain Province known as the Sand Hills, also were used in this study (fig. 1).

An initial list of 366 rural sites with annual peakflow record was compiled (fig. 1; table 1, p. 19-30). Records for these sites were then examined to determine the extent of available basin characteristic data and to identify sites with flows affected by channelization or regulation. The only consistently available basin characteristics for most sites were drainage area and location. A complete evaluation of all possible relations between flood discharges and other characteristics of rural basins requires a more complete set of basin characteristics. The computation and compilation of the required basin characteristics for all of the 366 initial sites are described in the following section.

Examination of the flow records for the 366 sites revealed 19 sites with record containing only regulated/ channelized flows, 27 sites with record that could be divided into periods of unregulated/unchannelized and regulated/channelized flows, and 320 sites with records unaffected by any known regulation/channelization. Of the 347 sites with at least some period of unregulated flow record, 317 sites had the requisite 10 or more years of record for computation of flood-frequency estimates (table 1). Flood-frequency estimates for these sites were computed and combined with the basin characteristics to form the data base that was used for the regional analyses (table 2, p. 31-42). This data base contained 222 sites in the Blue Ridge-Piedmont hydrologic area, 80 sites in the Coastal Plain hydrologic area, and 15 sites in the Sand Hills hydrologic area (table 2). Of the 46 sites with regulated flow records, floodfrequency estimates were computed for 42 sites with periods of regulated flow longer than 10 years but were not included in either regional analysis.

\section{Acknowledgments}

The authors gratefully acknowledge the assistance and support of Mr. Archie Hankins of the North Carolina Department of Transportation. The peak-flow data used in the analyses described herein were collected throughout North Carolina at stream gages operated in cooperation with a variety of Federal, State, and local agencies. The authors also would like to recognize the dedicated work of the USGS field 


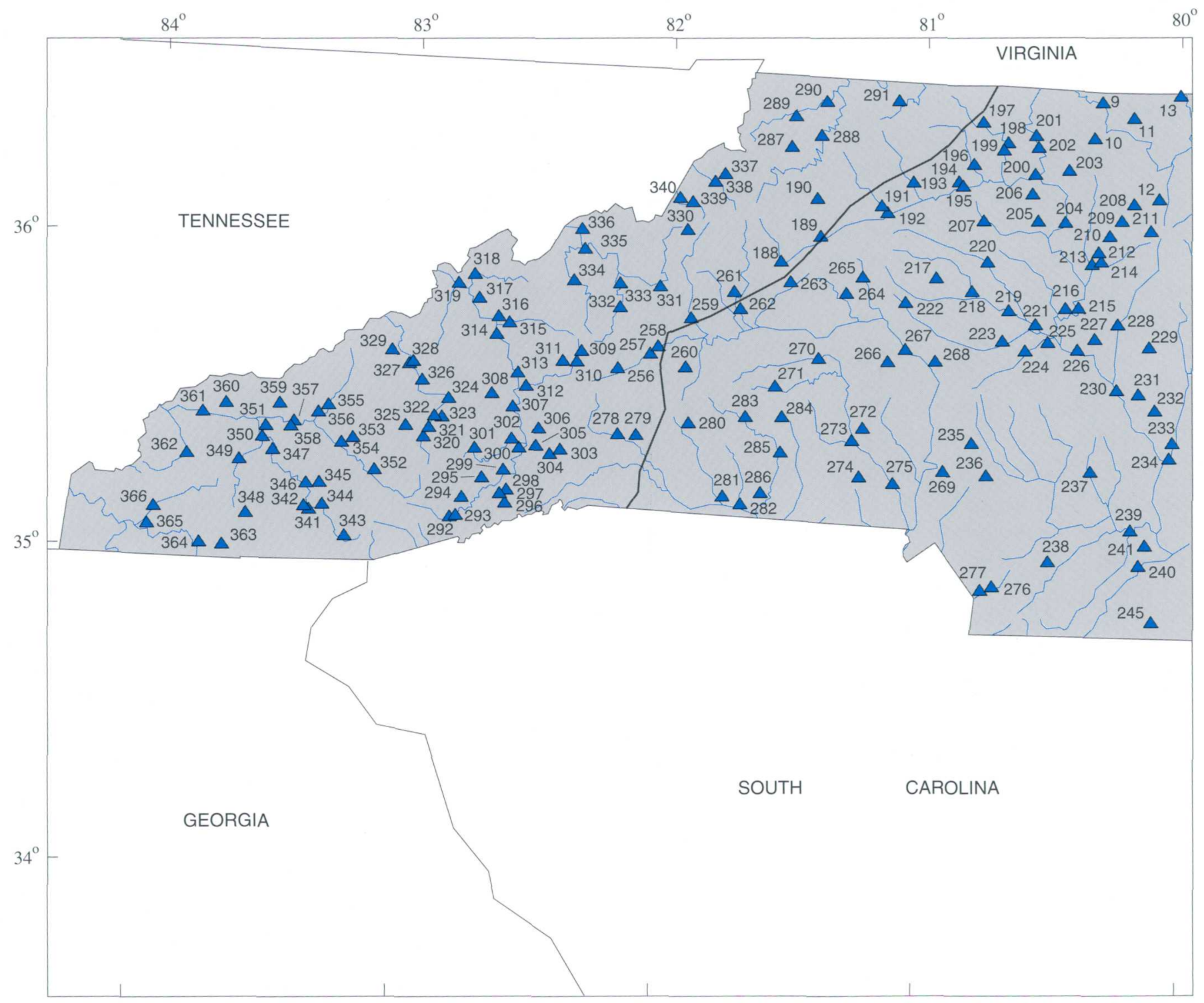

Figure 1. Locations of gaged rural sites in North Carolina. 


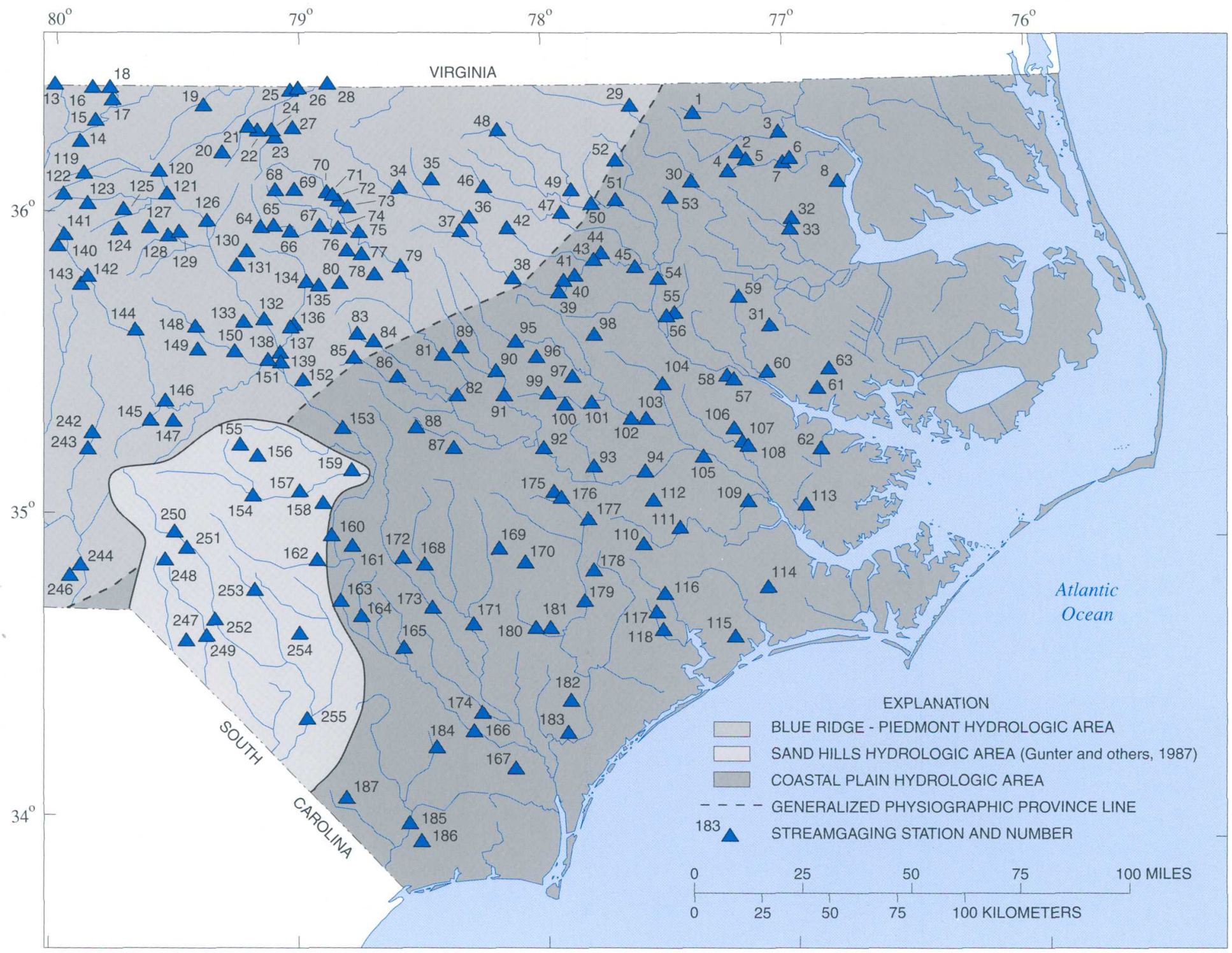


office staff in collecting, processing, and storing the peak-flow data necessary for the completion of this report.

\section{BASIN CHARACTERISTICS}

The annual peak-flow data that were used in this study were collected at gages in rural basins from all areas of the State, representing the wide range of physical and climatic conditions that occur in North Carolina. Eight parameters that characterize the size, shape, relief, and climate of rural basins in North Carolina were computed and compiled for each site used in the study. Physical basin characteristics include drainage area (DA), channel length (L), channel slope (CSLOPE), basin slope (BSLOPE), and basin shape (SHAPE) (table 3 ). The primary climatic characteristics relevant to flood frequency in each basin are the intensity, duration, and amount of storm rainfall, as well as other meteorologic inputs that control evaporation and transpiration. Lichty and Liscum (1978) suggested the use of a regional climate factor, $\mathrm{CF}_{\mathrm{t}}$, where $\mathrm{t}=2$-, $25-$, and 100 -year recurrence intervals, that integrates long-term rainfall and pan evaporation information and represents the effect of these climatic influences on flood frequency. In this study, a refined version of $\mathrm{CF}_{t}$, as developed and described by Lichty and Karlinger (1990), was used to characterize climatic effects of flood frequency. Climate factors, $\mathrm{CF}_{\mathrm{t}}$, for each site were computed by using a computer algorithm that used the maps of climate factor isolines presented in Lichty and Karlinger (1990) and the latitude and longitude of a site to interpolate values for the three climate factors, $\mathrm{CF}_{2}$, $\mathrm{CF}_{25}$, and $\mathrm{CF}_{100}$.

The hydrologic area for each site was determined by examining drainage boundary maps. The appropriate integer value for each site was then assigned to the region variable (REG) (table 3 ).

Other than drainage area, the physical basin characteristics selected for use in this study were not readily available for most of the basins in the study. In previous studies, drainage area was the primary explanatory variable; thus, there was no prior need to measure or compute the other characteristics. As a result, the other physical basin characteristics had to be computed and compiled. Because of the large number of sites involved and the need for consistent, unbiased methodology in making measurements and computations, a geographic information system (GIS)
Table 3. Basin characteristics that were used in the North Carolina flood-frequency regionalization study

$\left[\mathrm{mi}^{2}\right.$, square mile; mi, mile; $\mathrm{ft} / \mathrm{mi}$, foot per mile; ----, a dimensionless characteristic]

\begin{tabular}{|c|c|c|}
\hline $\begin{array}{c}\text { Basin } \\
\text { characteristic }\end{array}$ & $\begin{array}{c}\begin{array}{c}\text { Unit } \\
\text { of } \\
\text { measure }\end{array} \\
\end{array}$ & Definition \\
\hline \multicolumn{3}{|c|}{ Physical characteristics } \\
\hline $\mathrm{DA}$ & $\mathrm{mi}^{2}$ & $\begin{array}{l}\text { Drainage area, measured area } \\
\text { contained within basin } \\
\text { divides. }\end{array}$ \\
\hline $\mathrm{L}$ & $\mathrm{mi}$ & $\begin{array}{l}\text { Channel length, measured from } \\
\text { gage site upstream along } \\
\text { main channel to basin divide. }\end{array}$ \\
\hline CSLOPE & $\mathrm{ft} / \mathrm{mi}$ & $\begin{array}{l}\text { Channel slope, computed } \\
\text { between points at } 10 \text { - and } 85- \\
\text { percent of the length, } \\
\text { measured from the gage site. }\end{array}$ \\
\hline BSLOPE & $\mathrm{ft} / \mathrm{mi}$ & $\begin{array}{l}\text { Basin slope, mean value of } \\
\text { slope measured along several } \\
\text { flow paths from basin divide } \\
\text { to channel. }\end{array}$ \\
\hline SHAPE & ---- & $\begin{array}{l}\text { Shape, computed by dividing } \\
\text { drainage area by the square } \\
\text { of channel length }\left(\mathrm{DA} / \mathrm{L}^{2}\right)\end{array}$ \\
\hline \multicolumn{3}{|c|}{ Climatic characteristics } \\
\hline $\mathrm{CF}_{2}$ & $\cdots$ & $\begin{array}{l}\text { 2-year recurrence interval } \\
\text { climate factor }\end{array}$ \\
\hline $\mathrm{CF}_{25}$ & ---- & $\begin{array}{l}\text { 25-year recurrence interval } \\
\text { climate factor }\end{array}$ \\
\hline $\mathrm{CF}_{100}$ & ---- & $\begin{array}{l}\text { 100-year recurrence interval } \\
\text { climate factor }\end{array}$ \\
\hline \multicolumn{3}{|c|}{ Regional identifiers } \\
\hline BRP & --- & $\begin{array}{l}1 \text {, if site is in Blue Ridge- } \\
\text { Piedmont; } 0 \text {, if not. }\end{array}$ \\
\hline $\mathrm{CP}$ & ---- & $\begin{array}{l}\text { 1, if site is in Coastal Plain; } \\
0, \text { if not. }\end{array}$ \\
\hline SH & ---- & $\begin{array}{l}\text { 1, if site is in Sand Hills; } \\
0, \text { if not. }\end{array}$ \\
\hline REG & ---- & $\begin{array}{l}\text { 1, if site is in Blue Ridge- } \\
\text { Piedmont; } \\
\text { 2, if site is in Coastal Plain; } \\
\text { 3, if site is in Sand Hills. }\end{array}$ \\
\hline
\end{tabular}

was used to compute the required physical basin characteristics.

In order to use GIS to develop basin characteristics, a digital elevation model (DEM) was created by combining individual data sets. These data sets included the U.S. Environmental Protection Agency River File 3 (McKay and others, 1994), USGS digital line graph contour lines (U.S. Geological Survey, 1989), and the National Oceanic and Atmospheric Administration shoreline data set (National Oceanic and Atmospheric Administration, 
1999). Known drainage basin boundaries were overlain onto the DEM, and a combination of computer and visual interpolation techniques were used to define boundaries between the 366 gage sites and the known drainage boundaries.

Once the DEM was constructed and basin boundaries were delineated for all sites, a set of computer algorithms was developed to automatically compute drainage area, L, CSLOPE, BSLOPE, and SHAPE. Although GIS-computed drainage area was computed, the values used for DA were the drainage areas compiled from site records that were handcomputed and checked when the sites were established. The percent difference between GIS-computed drainage area and DA was automatically computed and used to verify the delineation of basin boundaries and the automated computations. Sites with greater than 10-percent difference between the computed drainage area and DA were flagged and re-examined. Errors in boundary delineation were corrected by comparing USGS 7.5-minute topographic maps with the original hand-delineated basin boundary and by using manual techniques to match the GIS basin boundary to the original. After adjusting basin boundaries, basin characteristics were recomputed and rechecked until satisfactory results were obtained. Several sites with drainage areas less than about 1 square mile $\left(\mathrm{mi}^{2}\right)$ did not meet the criteria of less that 10-percent difference between computed drainage area and DA because the resolution of the GIS data and computational methods were about one-tenth of a square mile. These sites were examined manually to determine if the automated delineation of basin boundaries was consistent with the hand-drawn boundaries; if not, the boundaries were adjusted accordingly and basin characteristics were recomputed.

\section{ESTIMATION OF FLOOD MAGNITUDE AND FREQUENCY AT GAGED SITES}

Flood-frequency estimates for a given stream site are typically presented as a set of exceedance probabilities or, alternatively, recurrence intervals along with the associated discharges. Exceedance probability is defined as the probability of exceeding a specified discharge in a 1-year period and is expressed as decimal fractions less than 1.0 or as percentages less than 100 . A discharge with an exceedance probability of 0.10 has a 10 -percent chance of being exceeded in any given year. Recurrence interval is defined as the number of years, on average, during which the specified discharge is expected to be exceeded one time and is expressed as number of years. A discharge with a 10-year recurrence interval is one that, on average, will be exceeded once every 10 years. Recurrence interval and exceedance probability are the mathematical inverses of one another; thus, a discharge with an exceedance probability of 0.10 has a recurrence interval of $1 / 0.10$ or 10 years. Conversely, a discharge with a recurrence interval of 10 years has an exceedance probability of one-tenth or 0.10 . It is important to remember that recurrence intervals, regardless of length, always refer to the average number of occurrences over a long period of time; for example, a 10-year flood discharge is one that might occur about 10 times in a 100 -year period, rather than exactly once every 10 years.

Flood-frequency estimates for gaged sites are computed by fitting the series of annual peak flows to some known statistical distribution. For the purposes of this study, estimates of flood-flow frequency are computed by fitting the logarithms (base 10) of the annual peak flows to a log-Pearson Type III distribution, following the guidelines and using the computational methods described in Bulletin 17B of the Hydrology Subcommittee of the Interagency Advisory Committee on Water Data (1982). The equation for fitting the log-Pearson Type III distribution to an observed series of annual peak flows is as follows:

$$
\log Q_{t}=\bar{X}+K S
$$

where

$Q_{t}$ is the $t$-year recurrence interval discharge in cubic feet per second,

$\bar{X}$ is the mean of the log-transformed annual peak flows,

$K$ is a factor dependent on recurrence interval and the skew coefficient of the logtransformed annual peak flows, and

$S$ is the standard deviation of the logtransformed annual peak flows.

Values for $K$ for a wide range of recurrence intervals and skew coefficients are published in Appendix 3 of Bulletin 17B (Hydrology Subcommittee of the Interagency Advisory Committee on Water Data, 1982). 
Fitting the log-Pearson Type III distribution to the general case of a long, well-distributed series of annual peak flows is fairly straightforward. Often, however, a series of peak flows may include low or high outliers, which are extremely low or high peak flows that depart significantly from the trend in the data. The gage record also may frequently include information about maximum peak flows that occurred outside of the period of regularly collected, or systematic, record. Such peak flows, known as historic peaks, are often the maximum peak flows known to have occurred during an extended period of time, longer than the period of collected record. The interpretation of outliers and historic peak information in the fitting process can greatly affect the final flood-frequency estimate.

Bulletin 17B (Hydrology Subcommittee of the Interagency Advisory Committee on Water Data, 1982) provides guidelines for detecting and interpreting these data points and provides computational methods for making appropriate corrections to the distribution to account for their presence. In some cases, high or low outliers are excluded from the record, so that the number of systematic peaks may not be equal to the number of years in the period of record.

Statistical measures, such as mean, standard deviation, or skew coefficient, can be described in terms of the sample or computed measure and the population or true measure. In terms of annual peak flows, the period of collected record can be thought of as a sample, or small portion, of the entire record, or population. Statistical measures computed from the sample record are estimates of what the measure would be if the entire population were known and used to compute the given measure. The accuracy of these estimates depends on the nature of the specific measure and the given sample of the population.

Skew coefficient measures the symmetry of the distribution of a set of peak flows about the median of the distribution. A peak-flow distribution with the mean equal to the median is said to have zero skew. A positively skewed distribution has a mean that exceeds the median typically as a result of one or more extremely high peak flows. A negatively skewed distribution has a mean that is less than the median typically because of one or more extremely low peak flows.

The computed skew coefficient for the peak-flow record of a given station is very sensitive to extreme events; therefore, the sample skew coefficient for short records may not provide an accurate estimate of the population skew. This is problematic because the $K$-factor in equation 1 for a given recurrence interval is dependent only on skew coefficient; therefore, an inaccurate skew coefficient will result in a floodfrequency estimate that is not representative of the true, or population, value.

A more accurate estimate of skew coefficient at a site can be obtained by using a weighted average of the sample skew coefficient estimate with a generalized, or regional, skew coefficient. A generalized skew coefficient is obtained by combining skew estimates from nearby, similar sites. A nationwide generalized skew study was conducted for the study documented in Bulletin 17B (Hydrology Subcommittee of the Interagency Advisory Committee on Water Data, 1982). Skew coefficients for long-term gage sites from all over the Nation were computed and used to produce a map of isolines of generalized skew. Gunter and others (1987) used this nationwide generalized skew in their flood-frequency computations. In addition, the USGS in North Carolina has computed other unpublished flood-frequency estimates by using the nationwide generalized skew.

During preliminary computations of floodfrequency estimates for inclusion in the regression analyses, a number of inconsistencies were noted between the computed values of sample skew coefficients at long-term gaging sites in North Carolina and the values obtained from the national generalized skew study. Inconsistencies at long-term sites are of concern because if generalized skew coefficients for a region are accurate estimates of the population skew, then the computed values of sample skew at long-term sites should approach the generalized values. Instead, it was noted that while sample skew coefficients at longterm North Carolina sites were somewhat consistent among themselves, they did not agree with the generalized values obtained from the nationwide generalized skew study. This anecdotal evidence, when considered along with the age and lack of resolution of the national study, was deemed sufficient cause to develop new generalized skew estimates for rural gaging sites in North Carolina.

Bulletin 17B (Hydrology Subcommittee of the Interagency Advisory Committee on Water Data, 1982) describes three methods for performing generalized skew studies using skew coefficients computed from long-term gaging stations-(1) plot computed skew 
coefficients on a map and construct skew isolines, (2) use regression techniques to develop a skew prediction equation that would relate station skew coefficients to some set of basin characteristics, or (3) use the arithmetic mean of computed skew coefficients from long-term sites in the area. For the purposes of this report, a modification of the second method initially was decided to be the most likely method to produce satisfactory results. However, rather than using ordinary least-squares regression, a weighted least-squares regression technique was used to determine the relation between the sample skew coefficient and selected basin characteristics. Sample skew estimates were weighted according to their respective record length; sites with long records were assigned greater weight than those with short records. The use of this regression technique in this study made it possible for data from all 347 sites with unregulated flows to be used in developing the estimate.

Multiple regression analysis, using ordinary least-squares regression, was used to determine the best set of basin characteristics to use as explanatory, or independent, variables in the weighted least-squares predictive model. Initial analyses were somewhat disappointing; no combination of basin characteristics accounted for a significant amount of the variance in computed skew. Lacking any significant statewide relationship between sample skew and basin characteristics, three location variables-BRP, CP, and $\mathrm{SH}$, one for each of the three hydrologic areas, Blue Ridge-Piedmont, Coastal Plain, and Sand Hills-were added to the analysis. For a given site, the location variable representing the region of the site was set at 1 , and the other two location variables were set at 0 (table 3). When these variables were added to the multiple regression analysis, results were only marginally better. None of the exploratory multiple regression models yielded significant relations between sample skew and the basin characteristics.

Given the lack of satisfactory results in this attempt to develop predictive equations relating skew to a set of basin characteristics, it was decided to apply a modified version of the second method in Bulletin 17B (Hydrology Subcommittee of the Interagency Advisory Committee on Water Data, 1982). A regional regression prediction equation was developed using weighted least-squares regression (Tasker and Stedinger, 1986). Weights were assigned, according to record length, to the computed skews for each site. Because the only statistically significant explanatory variable in the regression analysis was an indicator variable for the Sand Hills hydrologic area, the regression equation predicts one value for all sites in the Sand Hills area and another value for all sites in the remaining hydrologic areas. These predictions are essentially a weighted average of the sites in each of the two areas and, therefore, can be considered a modified version of the third method as well. The two weighted regional average skew values, along with the standard error of prediction and the mean square error of prediction associated with each estimate (table 4), were determined by the methods described in Tasker and Stedinger (1986).

Table 4. Generalized skew coefficient and associated mean square error for rural North Carolina gaging sites

\begin{tabular}{lccc}
\hline \multicolumn{1}{c}{ Hydrologic area } & $\begin{array}{c}\text { Generalized } \\
\text { skew } \\
\text { coefficient }\end{array}$ & $\begin{array}{c}\text { Standard } \\
\text { error }\end{array}$ & $\begin{array}{c}\text { Mean } \\
\text { square } \\
\text { error }\end{array}$ \\
\hline $\begin{array}{c}\text { Blue Ridge-Piedmont } \\
\text { and Coastal Plain }\end{array}$ & 0.195 & 0.194 & 0.038 \\
Sand Hills & 0.252 & 0.250 & 0.062 \\
\hline
\end{tabular}

As described previously, a weighted skew coefficient is used in order to improve the accuracy of the skew coefficient used to fit peak-flow records to a log-Pearson Type III distribution. The weighted skew coefficient for a given site is computed as the weighted average of the generalized skew coefficient and the site's computed skew coefficient, with weights assigned according to the mean square error of each component skew value. Flood-frequency estimates for all sites with unregulated flow records were computed by using the weighted skew method. Flood-frequency estimates for sites with regulated flow record were computed by fitting the recorded regulated peak flows to the logPearson Type III distribution. Computed sample skew coefficients for the regulated flow record were used because regulated peak-flow records typically are not representative of regional or generalized conditions. Although flood-frequency estimates for regulated sites are presented in this report, more detailed, site-specific analyses of flood frequency at many regulated sites are available from the U.S. Army Corps of Engineers. 


\section{ESTIMATION OF FLOOD MAGNITUDE AND FREQUENCY AT UNGAGED SITES}

Two regional analyses were used to develop methods for estimating flood discharges for ungaged rural basins in North Carolina. The first analysis, a traditional regional regression, required the use of generalized least-squares regression to define a set of predictive equations that relate peak discharges for the 2-, 5-, 10-, 25-, 50-, 100-, 200-, and 500-year recurrence intervals to selected basin characteristics for unregulated rural basins in each of three hydrologic areas of North Carolina (fig. 1). The second analysis, the region-of-influence method, required the development of a computer application to derive, for any given ungaged rural site in the Blue RidgePiedmont or Coastal Plain hydrologic areas, unique predictive relations between the 2-, 5-, 10-, 25-, 50-, 100-, 200-, and 500-year recurrence interval discharges and selected basin characteristics. Just as in the traditional regional regression, generalized leastsquares regression is used to develop these predictive relations; however, in the region-of-influence analysis, regression techniques are applied to only a selected subset of gaged sites, rather than the entire data base of gaged sites.

\section{Regional Regression Analysis}

Ordinary least-squares regression with flood discharge as the dependent variable was used in exploratory analyses to determine the best regression models for all combinations of the eight basin characteristics that were used as explanatory variables. An additional goal of the exploratory analysis was to determine if the subdivision of the State into three hydrologic areas is supported by current data.

Initially, the regionalization scheme used by Gunter and others (1987), which divided the State into the Blue Ridge-Piedmont, Coastal Plain, and Sand Hills hydrologic areas, was assumed to still be valid. Multiple regression analysis, using Mallow's $\mathrm{Cp}$ (Stedinger and Tasker, 1985), adjusted coefficient of determination, and hydrologic judgment as criteria, resulted in one-variable and two-variable models relating flood discharge to basin characteristics for each of the three hydrologic areas. The most significant one-variable models for all three regions included drainage area only. The most significant two-variable models included drainage area and the 25-year climate factor for the Blue Ridge-Piedmont and Sand Hills hydrologic areas; while the best two-variable models for Coastal Plain sites consisted of drainage area and channel length.

The validity of the regionalization scheme was examined by performing additional ordinary leastsquares regression analyses by using the two-variable models determined previously and comparing the coefficients and intercepts for each region's model to those for the rest of the State. In each case, the coefficients and intercepts for each region's model differed from those of the model using the remaining sites in the State. Additionally, a further test was conducted by introducing the location variable (table 3) for each region into the regression model. Each of these variables was set either at 1 , if the site was in a particular region, or 0 , if not. A five-variable ordinary least-squares regression model, including all available sites and using (1) drainage area, (2) climate factor, (3) location variable, (4) the product of the location variable with drainage area, and (5) the product of the location variable with climate factor as explanatory variables, was constructed for each recurrence interval discharge in each of the three hydrologic area. For a given region's model, a significant coefficient for the location variable indicates a difference in the intercept between sites in that region and sites in the rest of the State; a significant coefficient for either of the terms that are products of a location variable and another variable indicates a difference in the coefficients of the basin characteristic in that term between sites in that region and the rest of the State. In this particular test, a 95-percent confidence level was defined as significant. All three regional models had significant coefficients for at least one of the location variables or location variable product terms. Given the results of these regression tests, the regionalization scheme used by Gunter and others (1987) was accepted.

Ordinary least-squares regression is an appropriate and efficient regression model for use when flow estimates that are used as response variables are independent of each other (no correlation exists between pairs of sites) and when the reliability and variability of flow estimates that are used as response variables are approximately equal. The flow estimates that were used in this regression were generated from peak-flow records at gaging stations in all parts of North Carolina with periods of record ranging from 
10 to 101 years. Records from gaging stations on the same stream within the same basin or even in adjacent basins may be highly correlated because the peak flows resulted from the same rainfall events, similar antecedent conditions, and similar basin characteristics. However, records from other sites, in basins remote from each other, have varying degrees of correlation. In general, correlation between pairs of sites can be described as a function of distance between sites. Additionally, the reliability of flow estimates that were used as response variables in this regression is, in general, a function of record length and, as such, cannot be considered equal for all sites in the regression. Variability of the flow estimates, characterized by the standard deviation of the peak-flow record that was used to compute the flow estimate, depends in large part on characteristics of the basin and also cannot be considered equal for all sites used in the regression. For these reasons, ordinary least-squares regression was used only as an exploratory technique in this analysis to identify the best potential regression models and to evaluate the proposed regionalization scheme. The final regression equations were developed by using generalized least-squares regression techniques.

Generalized least-squares regression, as described by Stedinger and Tasker (1985), is a regression technique that takes into account the correlation between, as well as differences in the variability and reliability of, the flow estimates used as dependent, or response, variables. These factors are accounted for in generalized least-squares regression by assigning different weights to each observation of the response variable used in the regression, based on its contribution to the total variance of the sample-flow statistic used as the response variable. In contrast, ordinary least-squares regression assumes equal reliability and variability in flow estimates at all sites and no cross-correlation between flow records at all sites, so that each flow estimate has equal variance and is assigned equal weight in the regression.

The use of generalized least-squares regression techniques to model the relations between peak discharges and basin characteristics of North Carolina rural basins requires estimates of the cross-correlation coefficients and standard deviation of the peak-flow records that were used to compute peak discharges for the selected recurrence intervals. For each of the three hydrologic areas, a scatter-plot of sample correlation coefficients versus distance between sites was constructed for site pairs with long periods (at least
30 years) of concurrent record. A graphical 'best-fit' line to these points was used to define the relation between cross-correlation coefficient and distance between sites. This relation was then used to populate a cross-correlation matrix for the sites contained in each area. Variability of each peak-flow estimate is measured by the standard deviation of the peak-flow record used to compute that estimate. For each hydrologic area, a generalized least-squares regression of the sample standard deviations against drainage area was used to obtain estimates of the standard deviations of the peak-flow records at each site. These regression estimates of the standard deviations were used to assign weights to flow estimates because they are independent of the sample standard deviation estimates used to compute the flow estimate. Finally, length of record at each peak-flow site was used as a direct measure of the relative reliability of the flow estimates computed from those records.

Generalized least-squares regression was used to evaluate the 1- and 2-variable models suggested by preliminary ordinary least-squares regression for each of the three hydrologic areas in North Carolina. The final regression models in all of the regions relate peak discharge to drainage area for each recurrence interval (table 5). The 2-variable model for each region was tested by using generalized least-squares regression, and in each case, the addition of a second variable did not substantially improve the predictive ability of the model.

Table 5. North Carolina rural flood-frequency equations

[DA, drainage area, in square miles. Result will be in cubic feet per second]

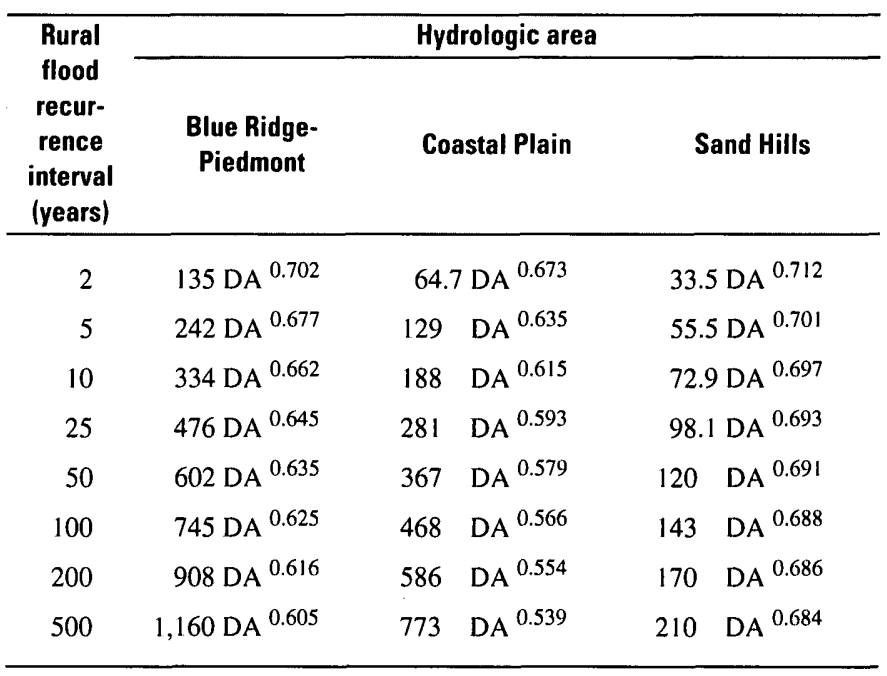


Uncertainty in a flow estimate that was predicted for an ungaged site by using the regression equations can be measured by the standard error of prediction, $S_{p}$, which is computed as the square root of the mean square error of prediction, MSEp. The MSEp is the sum of two components-the mean square error resulting from the model, $\gamma^{2}$, and the sampling mean square error, $M S E_{s, i}$, which results from estimating model parameters from samples of the population. The mean square model error, $\gamma^{2}$, is a characteristic of the model and is a constant for all sites. The mean square sample error, $M S E_{s, i}$, for a given site, however, depends on the values of the explanatory variables (DA) used to develop the flow estimate at that site. The standard error of prediction for a site, $i$, is computed as:

$$
S_{p, i}=\left(\gamma^{2}+M S E_{s, i}\right)^{\frac{1}{2}},
$$

and, therefore, varies from site to site. If the values of the explanatory variables for the gage sites used in the regression are assumed to be a representative sample of all sites in the region, then the average accuracy of prediction for the regression model can be determined by computing the average standard error of prediction:

$$
S_{p}=\left\{\gamma^{2}+\frac{1}{n} \sum_{i=1}^{n} M S E_{s, i}\right\}^{\frac{1}{2}}
$$

The standard error of the model $\left(S E_{(\text {model })}\right)$ can be converted from log (base 10) units to percent error by using the transformation formula,

$$
\% S E_{(\text {model })}=100\left(10^{2.3026\left(\gamma^{2}\right)}-1\right)^{\frac{1}{2}}
$$

Similarly, the average standard error of prediction can be transformed from $\log$ (base 10) units to percent error by substituting $S_{p}{ }^{2}$ for $\gamma^{2}$ in equation 4. Computation of $S_{p, i}$ for a given ungaged site, $i$, involves fairly complex matrix algebra. Computational procedures and the required matrices are provided in the Appendix.

The standard errors of the model, which measure how well the regression model fits the data used to construct it, ranged from about 34 percent to just over 57 percent. This error term is comparable to errors often cited and referred to as 'model error' or 'standard error of estimate' in earlier studies in which ordinary least-squares regression was used to develop predictive equations. The average standard errors of prediction, which provide a better overall measure of a model's predictive ability, ranged from about 36 percent to about 65 percent (table 6 ). Another measure of predictive ability is equivalent years of record (Hardison, 1971). Equivalent years of record are the number of years of peak-flow record needed to provide an estimate by using log-Pearson Type III techniques that would be equal in accuracy to an estimate made by using regional methods (table 6).

\begin{tabular}{|c|c|c|c|c|c|c|}
\hline \multirow{3}{*}{$\begin{array}{c}\text { Rural } \\
\text { flood } \\
\text { recurrence } \\
\text { interval } \\
\text { (years) }\end{array}$} & \multicolumn{6}{|c|}{ Hydrologic area } \\
\hline & \multicolumn{2}{|c|}{ Blue Ridge-Piedmont } & \multicolumn{2}{|c|}{ Coastal Plain } & \multicolumn{2}{|c|}{ Sand Hills } \\
\hline & $\begin{array}{l}\text { Average error } \\
\text { of prediction }\end{array}$ & $\begin{array}{c}\text { Equivalent } \\
\text { years } \\
\text { of record }\end{array}$ & $\begin{array}{c}\text { Average error } \\
\text { of prediction }\end{array}$ & $\begin{array}{c}\text { Equivalent } \\
\text { years } \\
\text { of record }\end{array}$ & $\begin{array}{l}\text { Average error } \\
\text { of prediction }\end{array}$ & $\begin{array}{l}\text { Equivalent } \\
\text { years } \\
\text { of record }\end{array}$ \\
\hline 2 & 41.2 & 2.0 & 37.9 & 2.9 & 38.4 & 2.1 \\
\hline 5 & 41.2 & 3.0 & 35.9 & 4.9 & 42.6 & 2.7 \\
\hline 50 & 45.9 & 6.4 & 39.8 & 10.1 & 53.1 & 4.6 \\
\hline 100 & 47.0 & 7.2 & 42.0 & 11.1 & 56.6 & 5.0 \\
\hline 200 & 48.9 & 7.9 & 44.2 & 11.9 & 60.2 & 5.4 \\
\hline 500 & 51.6 & 8.7 & 47.3 & 12.7 & 65.1 & 5.7 \\
\hline
\end{tabular}

Table 6. Average predictive errors, in percent, and equivalent years of record associated with North Carolina rural flood-frequency equations 


\section{Region-of-Influence Analysis}

The region-of-influence method (Tasker and Slade, 1994) estimates flood discharges at ungaged basins by deriving, for a given ungaged rural site, regression relations between the flood discharges and basin characteristics of a unique subset of gaged sites. This unique subset of gaged sites for a given ungaged site, first suggested by Acreman and Wiltshire (1987), was described by Burn (1990a, b) as the region of influence for an ungaged site, hence the name of the method. The unique subset of gaged sites is defined as the $\mathrm{N}$ 'nearest' gages to the ungaged site, where distance between sites $i$ and $j$ is defined by the Euclidean distance metric:

$$
d_{i j}=\left(\sum_{k=1}^{p}\left(\frac{x_{i k}-x_{j k}}{s d\left(X_{k}\right)}\right)^{2}\right)^{\frac{1}{2}},
$$

where

$d_{i j}$ is the distance between sites $i$ and $j$ in terms of basin characteristics,

$p$ is the number of basin characteristics used to calculate $d_{i j}$,

$X_{k}$ is the $k$ th basin characteristic, $s d\left(X_{k}\right)$ is the sample standard deviation for $X_{k}$, and

$x_{i k}$ is the value of $X_{k}$ at the $i$ th site.

This distance metric is directly analogous to the more familiar equation for distance, $D$, between two points, $\left(x_{1}, y_{1}\right)$ and $\left(x_{2}, y_{2}\right)$ in a 2 -dimensional rectangular coordinate system:

$$
D=\left[\left(x_{2}-x_{1}\right)^{2}+\left(y_{2}-y_{1}\right)^{2}\right]^{\frac{1}{2}} \text {, }
$$

where the only difference is the use of sample standard deviation to standardize the different basin characteristics and the slight notational difference of using an additional subscript $k$ rather than changing variable symbols $(x, y)$.

The distances, $d_{i j}$ 's, between a given ungaged site and all the gaged sites are computed and ranked; the $\mathrm{N}$ gaging stations with the smallest $d_{i j}$ compose the region of influence for that gaging station. Once determined, generalized least-squares regression techniques are used to develop the unique predictive relations between flood discharge and basin characteristics and estimates of the selected recurrence interval discharge at the ungaged site computed.

The number, $p$, and identity of the basin characteristics that are used to compute $d_{i j}$ and the number of gaged sites, $\mathrm{N}$, that compose the region of influence are specific to a given set of flood-discharge estimates and basin characteristics. In order to adapt the region-of-influence method to that data set, these parameters must be determined. In addition to these parameters, the set of basin characteristics also must be chosen for use as explanatory variables in the generalized least-squares regression models developed for each region. There is a subtle but important distinction between the two sets of basin characteristics - the first is used to define a region of influence; the second serves as variables in the unique predictive equations that are developed for that region of influence. These two sets of characteristics need not be identical but are in some cases. In other cases, such as in North Carolina, the set of characteristics used as variables is a subset of the set of characteristics used to define the region of influence.

Selection of the number of gaged sites, $\mathrm{N}$, and the number and identity of the basin characteristics that will define the region of influence for North Carolina was done by trial and error, using a computed root mean square error (RMSE) as the criterion. RMSE was computed by removing one site at a time from the data base and using the remaining sites to compute an estimate of the flow characteristic. Once completed for every site, the RMSE was computed as the square root of the arithmetic mean of the differences between the estimated and computed values at each site. The results of the exploratory multiple regression analyses performed as part of the traditional regional regression analysis were used to provide some insight in selecting initial sets of basin characteristics. The strong evidence for using separate hydrologic areas in the traditional regression analysis led to the decision to restrict a site's region of influence to its hydrologic area. As a result, 15 sites in the Sand Hills region (fig. 1) were not enough to support a valid region-of-influence analysis. For any ungaged site identified as a Sand Hills site, the same set of 15 sites would compose the region of influence, and the unique predictive equation developed would be the same equation developed by using traditional regional regression techniques, as described in previous sections of this report.

Combinations of defining variables that were tested include DA and $\mathrm{CF}_{25}$; DA and REG; DA, $\mathrm{CF}_{25}$, 
and REG; and DA, $\mathrm{CF}_{25}$, L, and REG. Each set of defining variables was tested by using values of 25,30 , and 35 for $\mathrm{N}$. For all variable combinations, $\mathrm{N}=30$ provided the best results; and the combination of variables that minimized RMSE for all recurrence intervals was DA, $\mathrm{CF}_{25}$, and REG. For these initial tests, DA and $\mathrm{CF}_{25}$ were used as explanatory variables in the unique regression relations. Subsequent testing, after the defining variables and $\mathrm{N}$ were determined, indicated that $\mathrm{CF}_{25}$ was not significant as an explanatory variable. As a result, only DA is used as an explanatory variable in the final version of the regionof-influence method.

After determining the best combination of variables to define the region of influence and the optimal value for $\mathrm{N}$, the computer application for the region of influence was completed. Equation 5 is used to determine the region of influence for an ungaged site, given the required input variables. Unique predictive equations for the ungaged site are then developed, using a generalized least-squares regression of the sites within the region of influence, and the predicted flood-discharge estimates are computed. In addition, because generalized least-squares regression was used to develop the predictive equations, $S_{p, i}$, the site-specific standard error of prediction is computed for each estimated recurrence interval discharge.

\section{Comparison of Results}

Application of the regional regression equations requires one less variable than application of the region-of-influence method. However, the additional variable, latitude and longitude of the ungaged site, is simple to determine, so that the variable requirements of the methods are nearly equal. The regional regression equations are easily evaluated manually, the region-of-influence method, however, is computationally intensive but is made simpler by the use of a computer application that performs the complex computations.

The average RMSE was computed for each area and recurrence interval (table 7), providing a measure of the predictive ability of the model or method.

Average RMSE was computed as the square root of the arithmetic mean of the differences between the floodfrequency estimate determined using the log-Pearson Type III and the flood-frequency estimate computed using either the regression equations or the region-ofinfluence method. RMSE for the region-of-influence method is slightly less than for the traditional regression equations in all cases. A site-specific comparison of predictive error also is possible by using $S_{p, i}$. As discussed previously, the region-of-influence method reports the site-specific standard error of prediction, $S_{p, i}$. The $S_{p, i}$ is not typically computed when evaluating the traditional regression equations manually because of the complexity of the computations involved. Automation of the equations eliminates this concern, and the $S_{p, i}$ is reported along with the flood-discharge estimate for any given site, allowing for comparison of predictive results on a siteby-site basis.

Table 7. Root mean square error, in percent, for the regional regression and region-of-influence methods, presented by hydrologic area and recurrence interval

[n.a., not applicable]

\begin{tabular}{|c|c|c|c|c|c|c|}
\hline \multirow{3}{*}{$\begin{array}{l}\text { Recurrence } \\
\text { interval }\end{array}$} & \multicolumn{6}{|c|}{ Hydrologic area } \\
\hline & \multicolumn{2}{|c|}{ Blue Ridge-Piedmont } & \multicolumn{2}{|c|}{ Coastal Plain } & \multicolumn{2}{|c|}{ Sand Hills } \\
\hline & $\begin{array}{l}\text { Regional } \\
\text { regression }\end{array}$ & $\begin{array}{c}\text { Region } \\
\text { of } \\
\text { influence }\end{array}$ & $\begin{array}{l}\text { Regional } \\
\text { regression }\end{array}$ & $\begin{array}{c}\text { Region } \\
\text { of } \\
\text { influence }\end{array}$ & $\begin{array}{l}\text { Regional } \\
\text { regression }\end{array}$ & $\begin{array}{c}\text { Region } \\
\text { of } \\
\text { influence }\end{array}$ \\
\hline 2 & 43.9 & 42.9 & 39.3 & 34.4 & 40.9 & n.a. \\
\hline 5 & 45.4 & 43.3 & 38.6 & 34.6 & 46.1 & n.a. \\
\hline 10 & 47.4 & 44.7 & 40.5 & 37.1 & 50.3 & n.a. \\
\hline 25 & 50.7 & 47.3 & 44.4 & 41.7 & 55.9 & n.a. \\
\hline 50 & 53.4 & 49.5 & 47.9 & 45.6 & 60.3 & n.a. \\
\hline 100 & 56.2 & 51.9 & 51.6 & 49.7 & 64.7 & n.a. \\
\hline 200 & 59.2 & 54.4 & 55.7 & 53.9 & 69.3 & n.a. \\
\hline 500 & 63.1 & 57.9 & 61.1 & 59.6 & 75.4 & n.a. \\
\hline
\end{tabular}


In general, little difference was found in the ease of application or in average predictive abilities between the regional regression equations and the region-ofinfluence method. The region-of-influence method is a new technique and is still being improved. As a result, the region-of-influence method is considered a secondary or alternative method of determining floodfrequency estimates for ungaged rural sites in North Carolina.

\section{Use of Computer Software}

As part of the study described by this report, a computer software package was developed that computes (1) estimates of flood-frequency discharges using the region-of-influence method at ungaged rural sites in the Blue Ridge-Piedmont or Coastal Plain hydrologic areas of North Carolina, (2) estimates of flood-frequency discharges using the regional regression equations for ungaged rural sites in each of the three hydrologic areas of North Carolina, and (3) the associated site-specific errors of prediction, $S_{p, i}$, for each method. The complexity of the computations required for the region-of-influence method requires the use of the software for practical application of the method. The regional regression equations can be evaluated manually, but the software allows for easy evaluation of the complex computation of the $S_{p, i}$ for the regional regression method.

The computer software package includes an executable program file and four supporting data files. All five files are required for execution of the computer software. The software package and instructions for down loading, installation, and execution of the program currently are available at the North Carolina District home page on the World Wide Web at URL <http://nc.water.usgs.gov/reports/wri014207>.

\section{APPLICATION OF METHODS}

The methods presented in this report can be used to estimate the 2-, 5-, 10-, 25-, 50-, 100-, 200-, and 500year recurrence interval flood discharges at gaged and ungaged, unregulated, rural sites in North Carolina. Use of either the regional regression equations or the region-of-influence method requires estimates of the input variables. To apply these methods, first locate the ungaged site on a map and identify in which hydrologic area the site is located. An estimate of the latitude and longitude of the site is required for the region-ofinfluence method. Next, delineate the drainage boundaries of the ungaged site and measure the drainage area contained within those boundaries. The corresponding regression equations (table 5) can then be applied to determine an estimate of the flood discharges for the recurrence interval of interest. Alternatively, the region-of-influence computer application can be initiated; it will query the user for an output file name, an identifier for the site of interest, the hydrologic area for the site, the drainage area of the site, and the latitude and longitude of the site. With this information, the computer application computes the climate factor, defines a region of influence, and produces the desired flood-discharge estimates, along with the standard error of prediction, $S_{p, i}$, specific to the ungaged site.

The computer application contains the regression equations and can be used to apply either method. Use of the computer application to evaluate the regression equation provides an automated computation of $S_{p, i}$ for the regression equations as well as for the region-of-influence method. If evaluated manually, $S_{p, i}$ can be computed only by using the rather complex computational procedures described previously and outlined in detail in the Appendix. Although average standard errors of prediction (table 6) give an idea of the relative accuracy of the methods; $S_{p, i}$ is the more precise measure of the accuracy of a specific prediction.

Flood-frequency estimates at gaged sites and ungaged sites on the same stream as a gaged site can be improved by combining the estimate determined by regional methods with the estimate determined by fitting the log-Pearson Type III distribution to the peakflow record at the gaged site. At a gaged site, the best estimate of flood frequency can be determined by

$$
Q_{t}(w)=\frac{Q_{t}(g) N+Q_{t}(r) E Y}{N+E Y}
$$

where

$Q_{t}(w)$ is the weighted discharge for recurrence interval $t$

$Q_{t}(g)$ is the discharge for recurrence interval $t$ determined using peak-flow record from the gaged site;

$Q_{t}(r)$ is the discharge for recurrence interval $t$ determined using regional methods;

$N$ is the number of systematic peaks in the gaged sites record; and

$E Y$ is the equivalent years of record from table 6 . 
Flood estimates at an ungaged site that is on the same stream as a gaged site can be determined by using a combination of the regional estimate and the logPearson Type III estimate from the nearby gaged site. In order to make the appropriate adjustment, first compute the ratio,

$$
R=\frac{Q_{t}(w)}{Q_{t}(r)},
$$

for the gaged site by using $Q_{t}(w)$ and $Q_{t}(r)$ as defined in the preceding paragraph. Next, a correction factor, $R^{\prime}$, is computed as follows:

$$
R^{\prime}=R-\frac{\Delta D A(R-1)}{0.5 D A_{g}}
$$

where $\triangle D A$ is the absolute value of the difference between the drainage areas of the gaged and ungaged sites, and $D A_{g}$ is the drainage area of the gaged site. If $\triangle D A / D A_{g}$ is less than 0.5 , then the corrected discharge for the ungaged site, $Q_{t}$ (corr), can be computed by multiplying the correction factor, $R$ ', by the regional estimate for the ungaged site, $Q_{t}(r)$. If $\triangle D A / D A_{g}$ is greater than 0.5 , use the results of the regional methods without correction.

At times, flood-frequency estimates may be desired for an ungaged site that is between two gaged sites on the same stream. In this case, select the gaged site for which $\triangle D A / D A_{g}$ is less than 0.5 , compute $R$, and apply as described above. If $\triangle D A / D A_{g}$ is less than 0.5 for both gaged sites, compute $R^{\prime}$ for each. If both correction factors are greater than 1.0, use the larger $R^{\prime}$; if both correction factors are less than 1.0, use the smaller $R^{\prime}$. If one correction factor is greater than 1.0 and the other smaller than 1.0, an average of the two correction factors should be used.

If the drainage basin for an ungaged site lies within more than one hydrologic area, the computed discharge should be adjusted according to the proportion of the total drainage area that lies within each hydrologic area. The adjusted discharge can be determined by the equation:

$$
\begin{gathered}
Q_{t}(\text { adjusted })=Q_{t}(H A 1) x \frac{D A_{1}}{D A_{\text {total }}} \\
+Q_{t}(H A 2) x \frac{D A_{2}}{D A_{\text {total }}},
\end{gathered}
$$

where $Q_{t}$ (adjusted) is the adjusted discharge for the $t$-year recurrence interval; $Q_{t}(H A 1)$ and $Q_{t}(H A 2)$ are the discharges computed as if the entire drainage area were within the hydrologic areas, $H A 1$ and $H A 2 ; D A_{1}$ and $D A_{2}$ are portions of the total drainage area found in the respective hydrologic drainage areas; and $D A_{\text {total }}$ is the total drainage area.

\section{SUMMARY}

Accurate and reliable estimates of the magnitude and frequency of floods are critical for such activities as bridge design, flood-plain delineation and management, water-supply management, and management of water-control structures, among others. Recognizing the need for accurate estimates of flood frequency at ungaged rural basins, the U.S. Geological Survey, in cooperation with the North Carolina Department of Transportation, conducted a study to further define the relation between flood discharges of selected recurrence intervals and selected physical and climatic characteristics of rural North Carolina basins. This study includes the development of two methods for regionalizing, or extending in space, flood-frequency estimates at gaged sites. In the first method, traditional regional regression analysis, a generalized leastsquares regression analysis is used to develop a set of predictive equations for each of three hydrologic areas in North Carolina-the Blue Ridge-Piedmont, the Coastal Plain, and the Sand Hills. In the second method, the region-of-influence method, floodfrequency estimates for ungaged sites are predicted interactively, based on data from a subset of gaged sites with basin characteristics similar to those of the ungaged site. This report documents the development of both methods, using a data base of flood-discharge estimates and basin characteristics for 317 rural North Carolina gaged sites.

An initial set of 366 gaged sites was determined to have some annual peak-flow record; basin characteristics data were computed and compiled for all of these sites by using a GIS. While the development of the basin characteristics was ongoing, flow records were examined to determine which sites had flows that were affected by regulation or channelization. Of the 366 original sites, 19 sites had only regulated record and 27 sites had periods of unregulated flow record prior to regulation. After basin characteristics were developed and flow records were examined, preliminary computations of flood-frequency estimates 
were begun. Results of these preliminary computations indicated the need for a generalized skew study for North Carolina basins to replace outdated generalized skews that were based on a nationwide study. After the generalized skew study, flood-frequency estimates for all sites with 10 or more years of record were computed. Flood-frequency estimates were computed for 317 rural, unregulated sites and for 42 rural, regulated sites. The sites with regulated record were excluded from further analysis.

Basin characteristics data and flood-frequency estimates for the 317 rural, unregulated sites were merged to form the data base that was used to develop the regional regression equations and the region-ofinfluence method. Of the 317 total sites, 222 were located in the Blue Ridge-Piedmont hydrologic area, 80 were located in the Coastal Plain hydrologic area, and 15 were located in the Sand Hills hydrologic area. Preliminary multiple regression analyses, using ordinary least-squares regression, were conducted to confirm the validity of the regionalization scheme and to identify the best combination of explanatory variables for inclusion in the generalized least-squares analysis.

Generalized least-squares analysis was used to develop a set of equations for each region that relates the 2-, 5-, 10-, 25-, 50-, 100-, 200-, and 500-year recurrence interval flood discharges to drainage area. Model error and error of prediction for the equations ranged from about 40 percent for the lower recurrence interval equations to more than 50 percent, with two equations for the Sand Hills indicating more than 60 percent.

The region-of-influence method was adapted to the available flood-frequency and basin characteristics data for North Carolina. The drainage area, hydrologic area, and latitude and longitude of an ungaged site in either the Blue Ridge-Piedmont or Coastal Plain hydrologic areas of North Carolina are required to predict the 2-, 5-, 10-, 25-, 50-, 100-, 200-, and 500year recurrence interval flood discharges for a specified ungaged site. The Sand Hills hydrologic area did not have a sufficient number of sites to apply the region-ofinfluence method. Because of the complexity of the computations involved in the region-of-influence method, a computer application is required for the practical use of the method.

A brief comparison of the regional regression and region-of-influence methods, based on ease of application and RMSE of prediction, resulted in neither method being clearly superior. Both require hydrologic area and drainage area as input variables; the region-ofinfluence method additionally requires latitude and longitude, but these coordinates are fairly simple to determine. The RMSE were, in general, lower for the region-of-influence method, but only slightly. The region-of-influence method is newly developed and still being refined. As a result, the regional regression equations are considered to be the primary method of estimating magnitude and frequency of floods for rural ungaged sites in North Carolina. The region-ofinfluence method can be considered an alternative method.

A computer application is available that automates the complex computations required by the region-of-influence method. This computer application includes the option to compute flood-frequency estimates using the predictive equations developed by the traditional regional regression analysis. The computer application also computes site-specific error of prediction for each method.

\section{REFERENCES}

Acreman, M.C., and Wiltshire, S.E., 1987, Identification of regions for regional flood frequency analysis [abs.], EOS, v. 68, no. 44.

Burn, D.H., 1990a, An appraisal of the "region of influence" approach to flood frequency analysis: Hydrological Sciences Journal, v. 35, no. 24, p. 149-165.

1990b, Evaluation of regional flood frequency analysis with a region of influence approach: Water Resources Research, v. 26, no. 10, p. 2257-2265.

Gunter, H.C., Mason, R.R., and Stamey, T.C., 1987, Magnitude and frequency of floods in rural and urban basins of North Carolina: U.S. Geological Survey Water-Resources Investigations Report 87-4096, $52 \mathrm{p}$.

Hardison, C.H., 1971, Prediction error of regression estimates of streamflow characteristics at ungaged sites: U.S. Geological Survey Professional Paper 750-C, p. C228-C236.

Hodge, S.A., and Tasker, G.D., 1995, Magnitude and frequency of floods in Arkansas: U.S. Geological Survey Water-Resources Investigations Report 95-4224, $52 \mathrm{p}$.

Hydrology Subcommittee of the Interagency Advisory Committee on Water Data, 1982, Guidelines for determining flood frequency: U.S. Geological Survey Bulletin 17B, Office of Water Data Collection, Reston, Va., $183 \mathrm{p}$. 
Lichty, R.W., and Karlinger, M.R., 1990, Climate factor for small-basin flood frequency: American Water Resources Association, Water Resources Bulletin, v. 26 , no. 4 , p. $577-586$.

Lichty, R.W., and Liscum, F., 1978, A rainfall-runoff modeling procedure for improving estimates of T-year annual floods for small drainage basins: U.S.

Geological Survey Water-Resources Investigations 78-7, $44 \mathrm{p}$.

McKay, L., Hanson, S., Horn, R., Dulaney, R., Cahoon, A., Olsen, M., and Dewald, T., 1994, The U.S. EPA Reach File Version 3.0 Alpha Release (RF3-Alpha) Technical Reference: U.S. Environmental Protection Agency, Washington, D.C.

National Oceanic and Atmospheric Administration, 1999, NOAA's medium resolution digital vector shoreline, accessed March 17, 1999, at URL http:// seaserver.nos.noaa.gov/projects/shoreline.html.
Stedinger, J.R., and Tasker, G.D., 1985, Regional hydrologic analysis 1-Ordinary, weighted, and generalized least square compared: American Geophysical Union, Water-Resources Research, v. 21, no. 9, p. 1421-1432.

Tasker, G.D., and Slade, R.M., 1994, An interactive regional regression approach to estimating flood quantiles, in Fontane, D.G., and Tuvel, H.N., eds., Proceedings of the Twenty-First Annual Conference, Water policy and management, solving the problems, May 23-26, 1994: Denver, Colo., Denver Society of American Society of Civil Engineers, p. 782-785.

Tasker, G.D., and Stedinger, J.R., 1986, Regional skew with weighted LS regression: Journal of Water Resources Planning and Management, v. 112, no. 2, p. 225-237. 1989, An operational GLS model for hydrologic regression: Journal of Hydrology, v. 111, p. 361-375.

U.S. Geological Survey, 1989, Digital line graphs from 1:100,000-sćale maps, National Mapping Program Technical Instructions Data Users Guide 2, 88 p. 


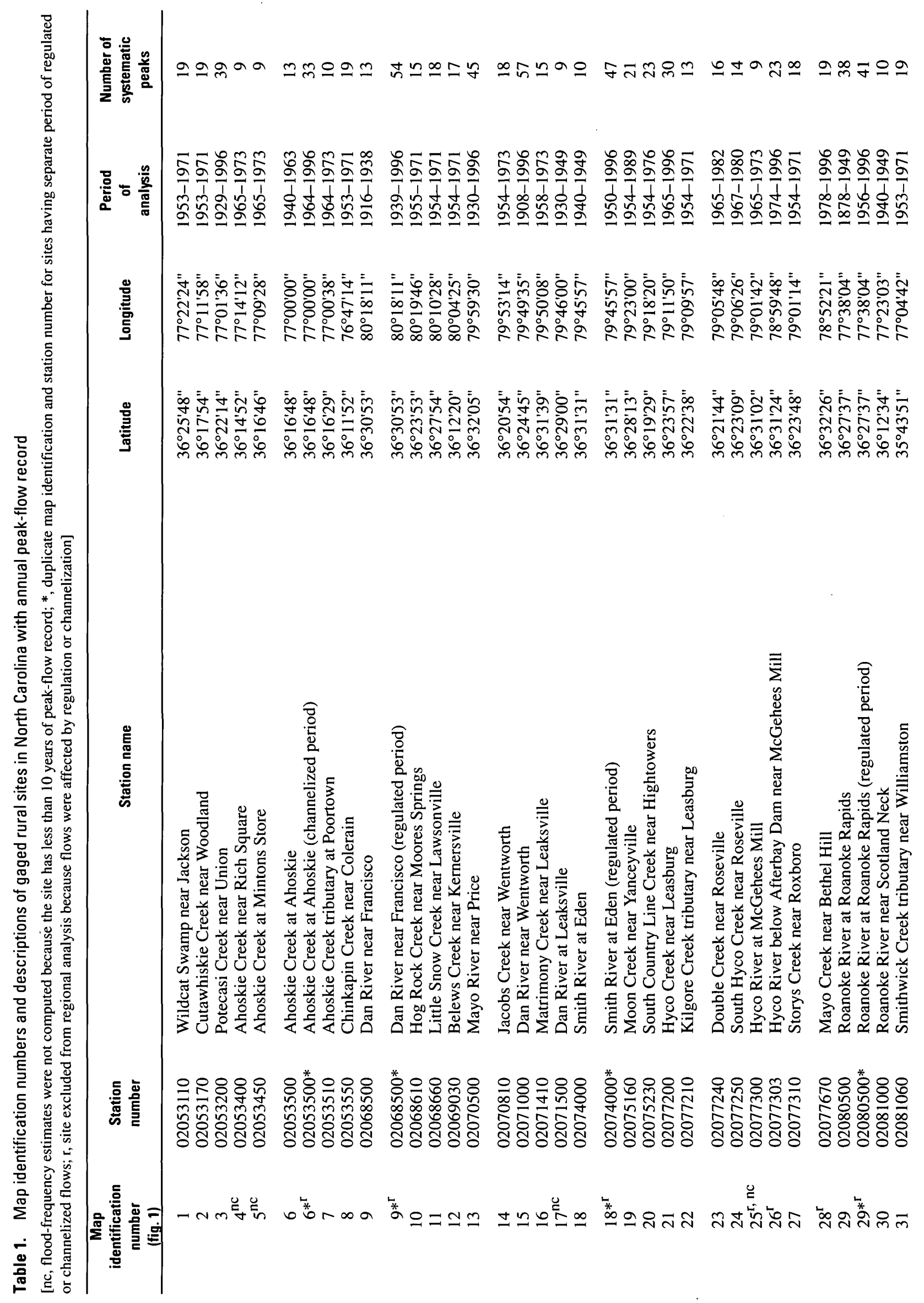




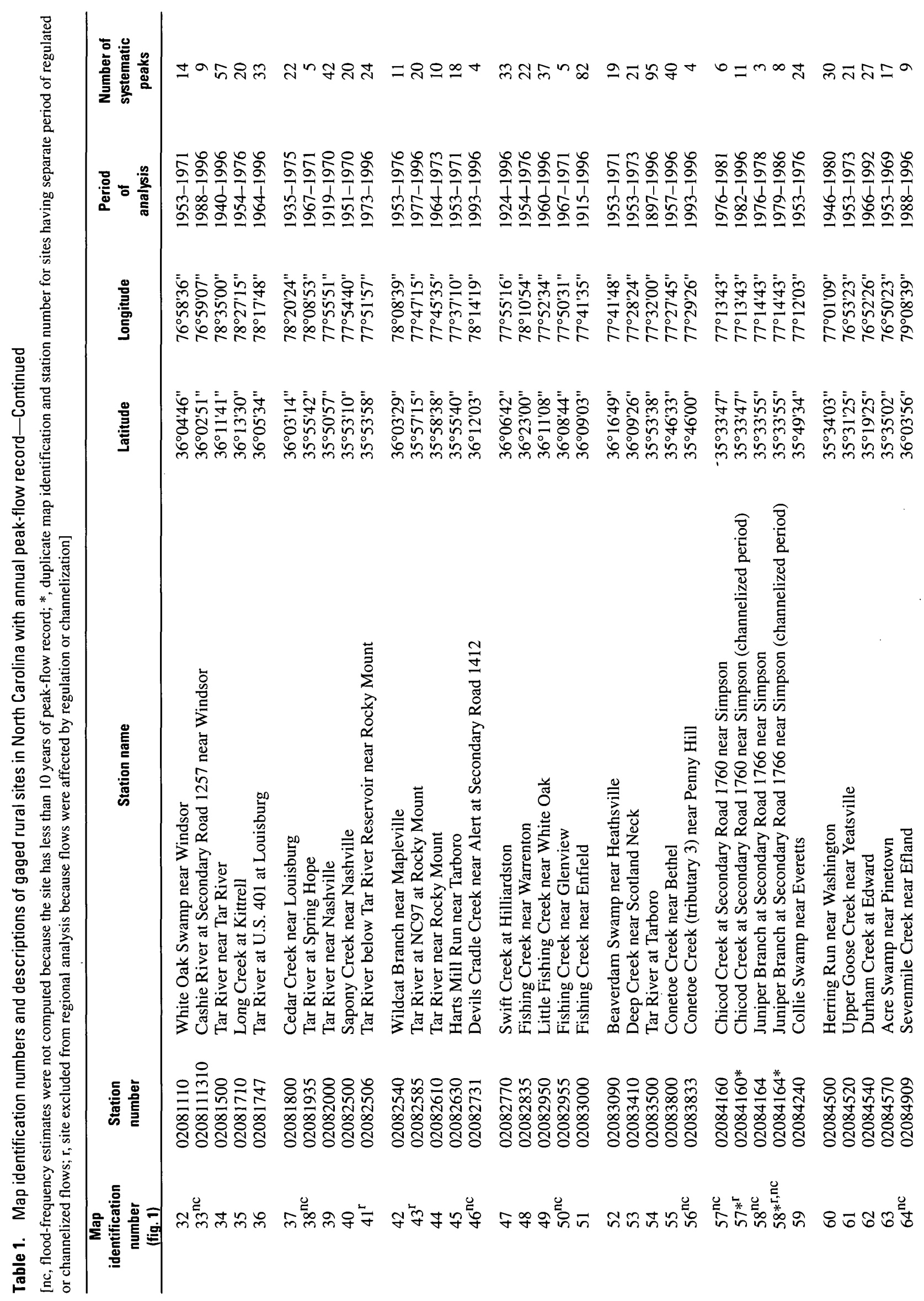




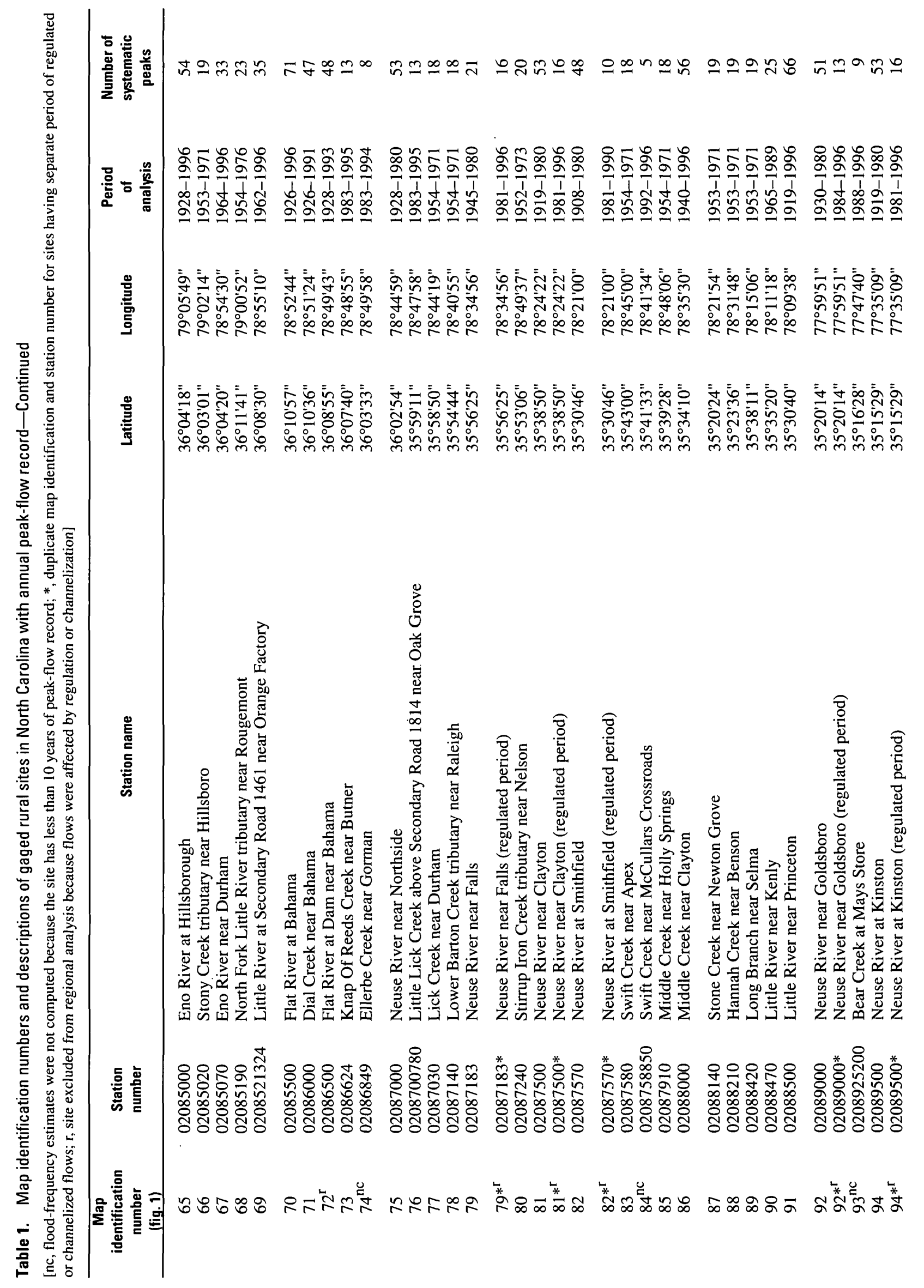




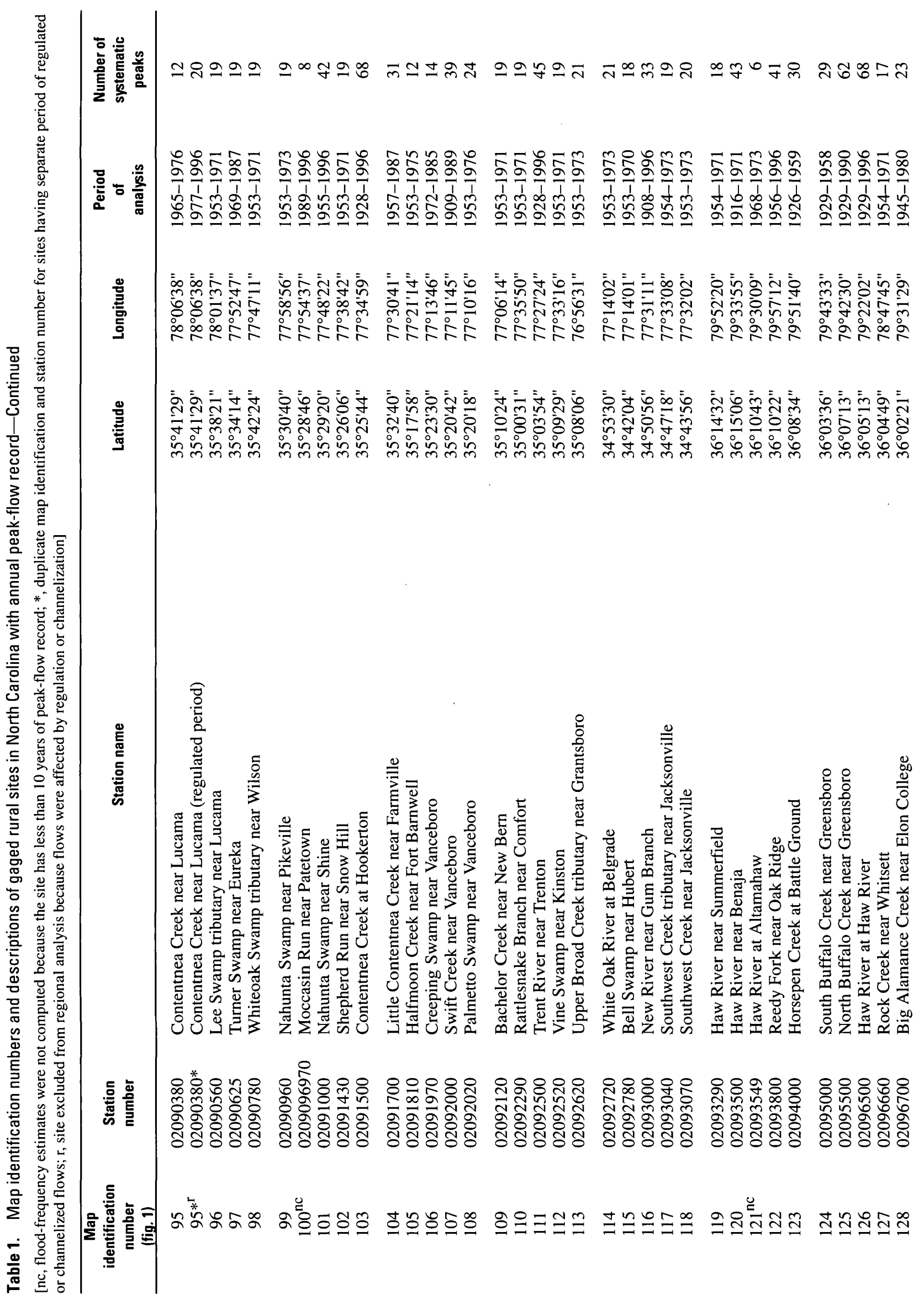




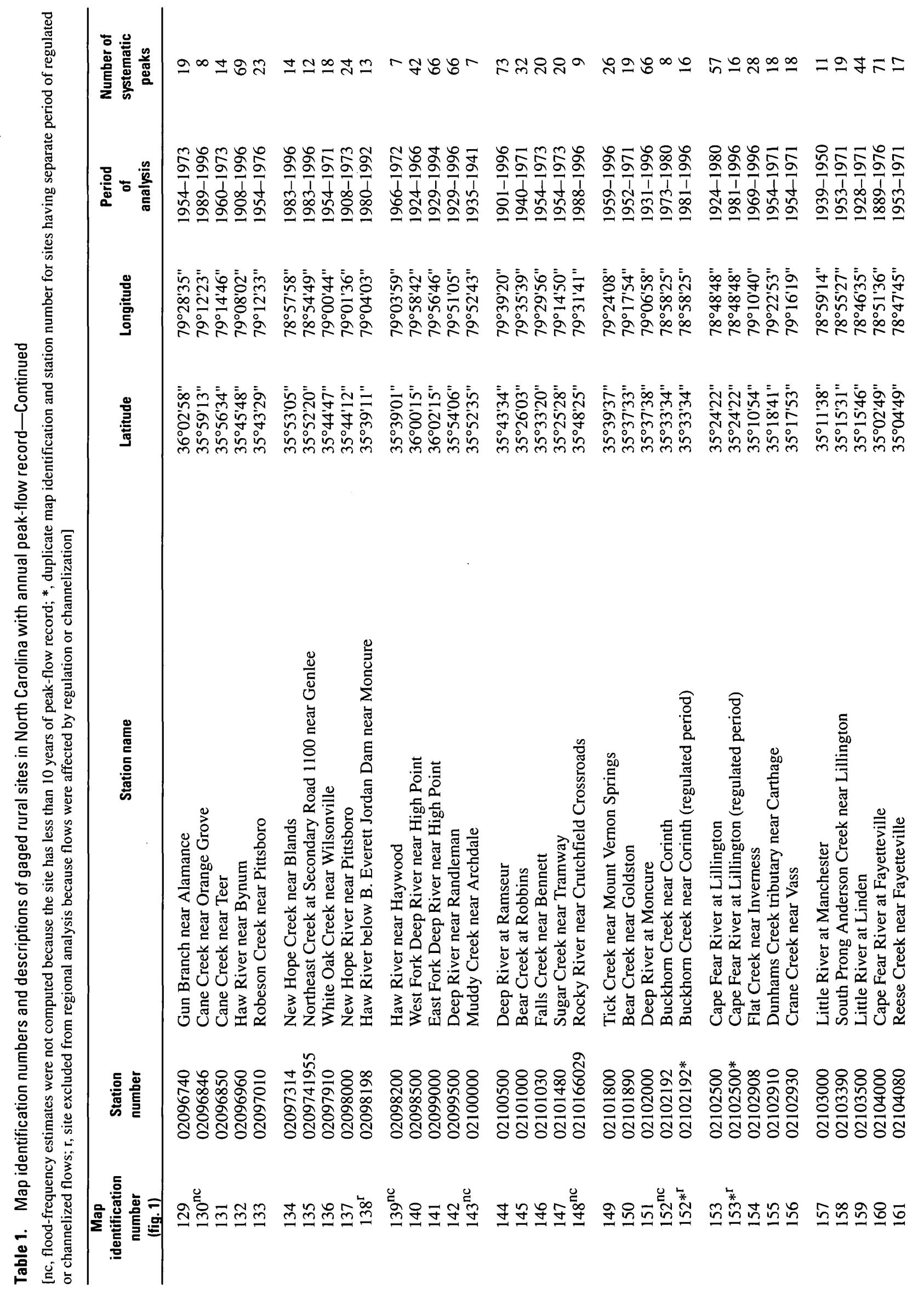




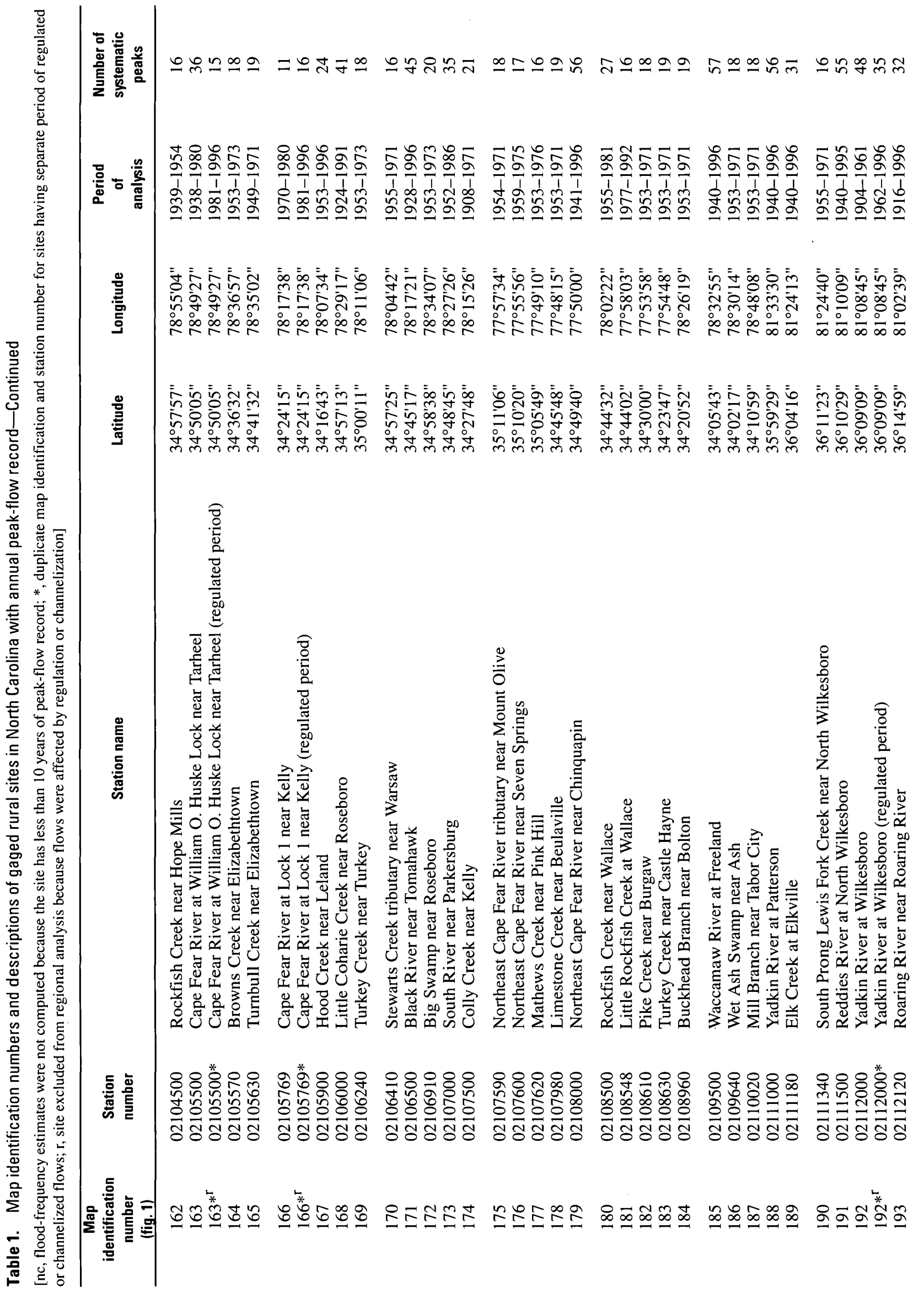




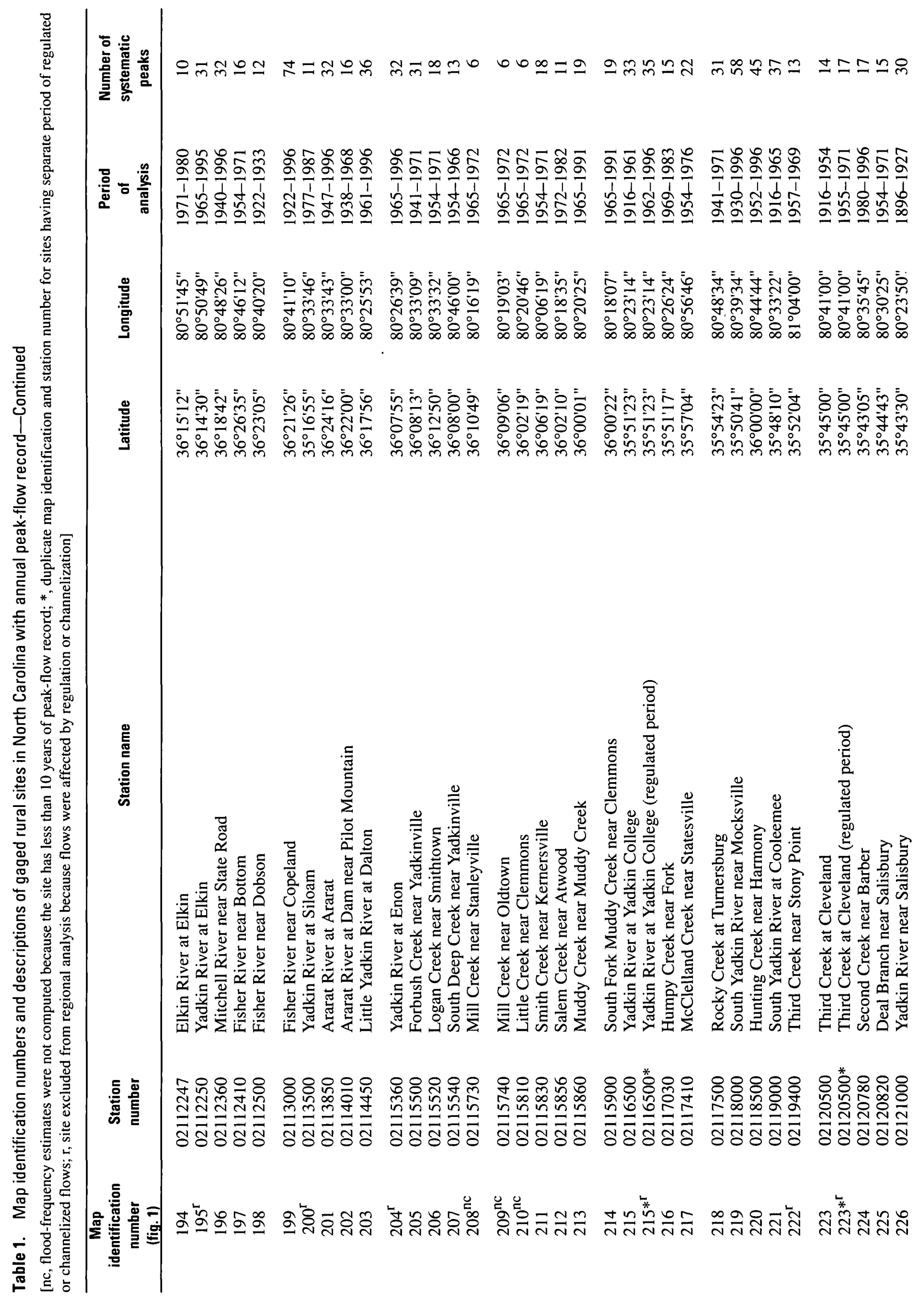




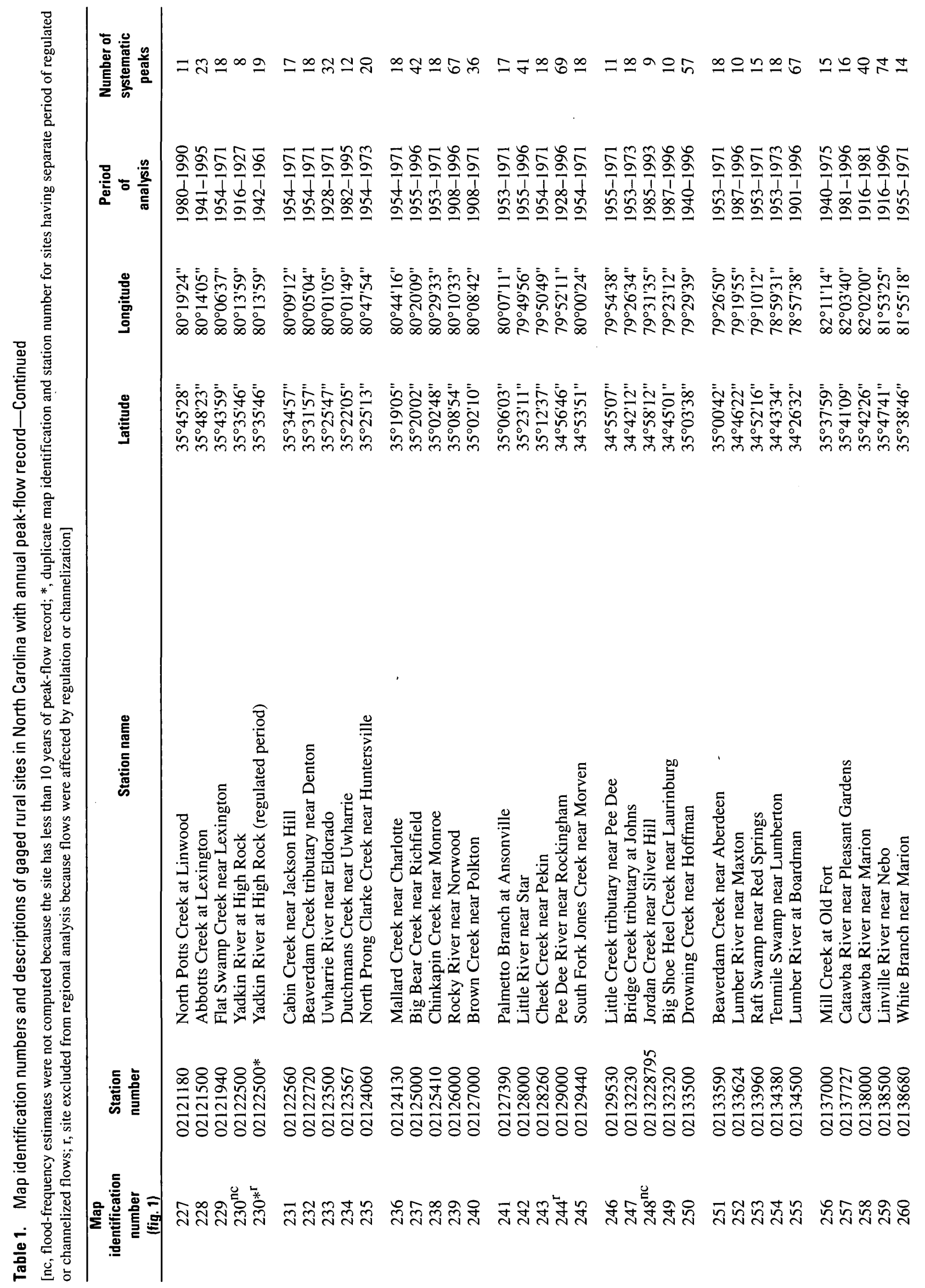




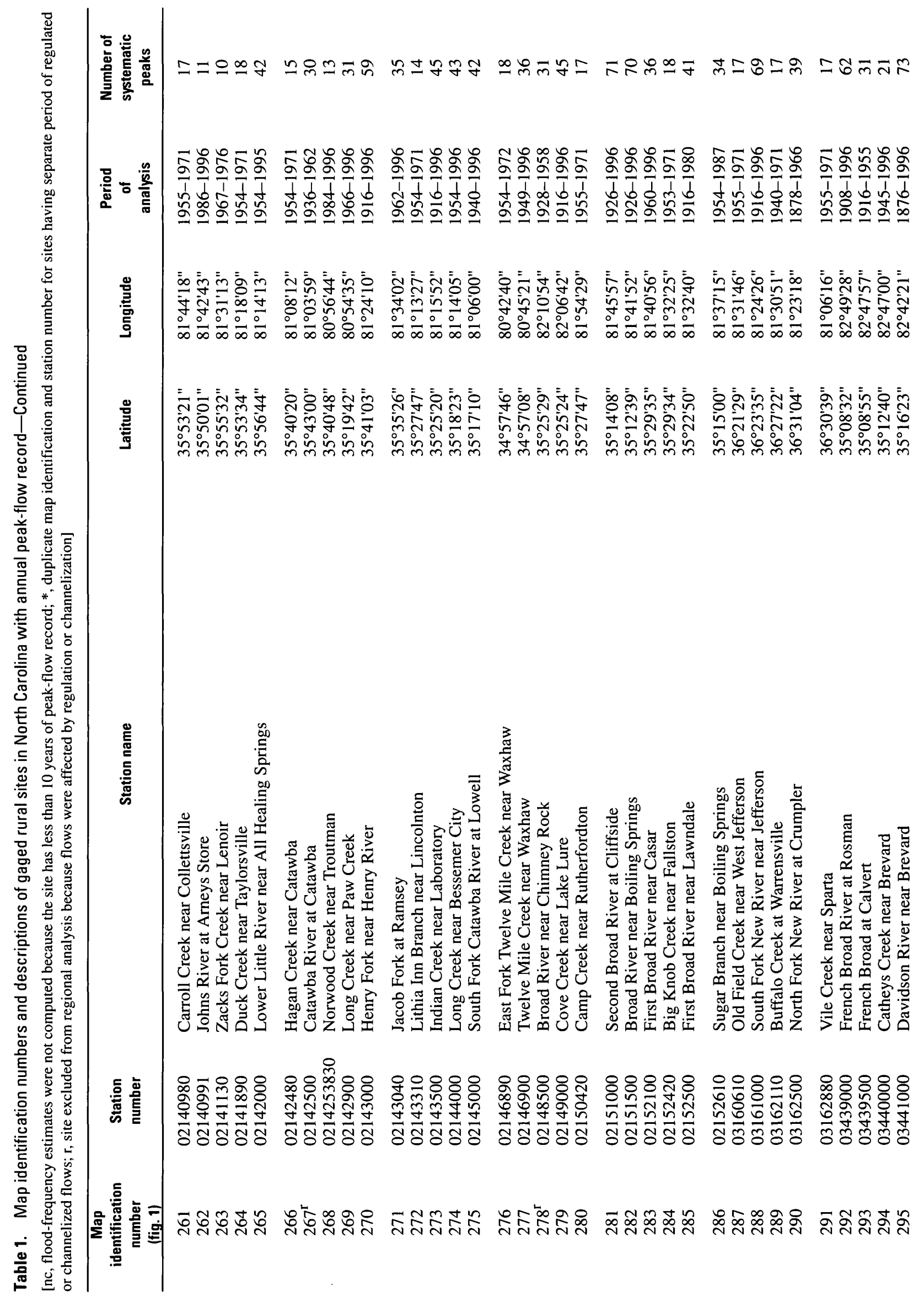




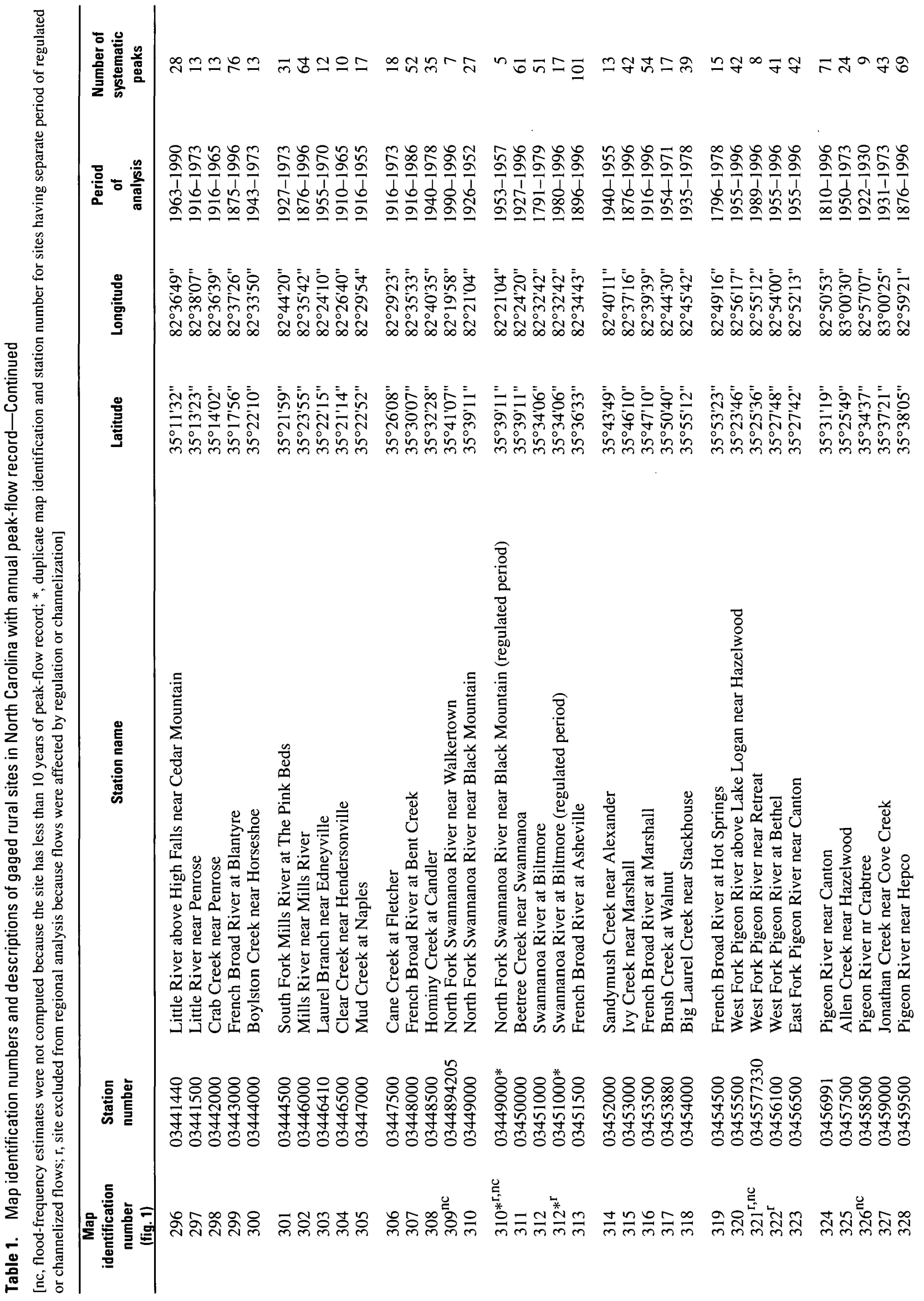




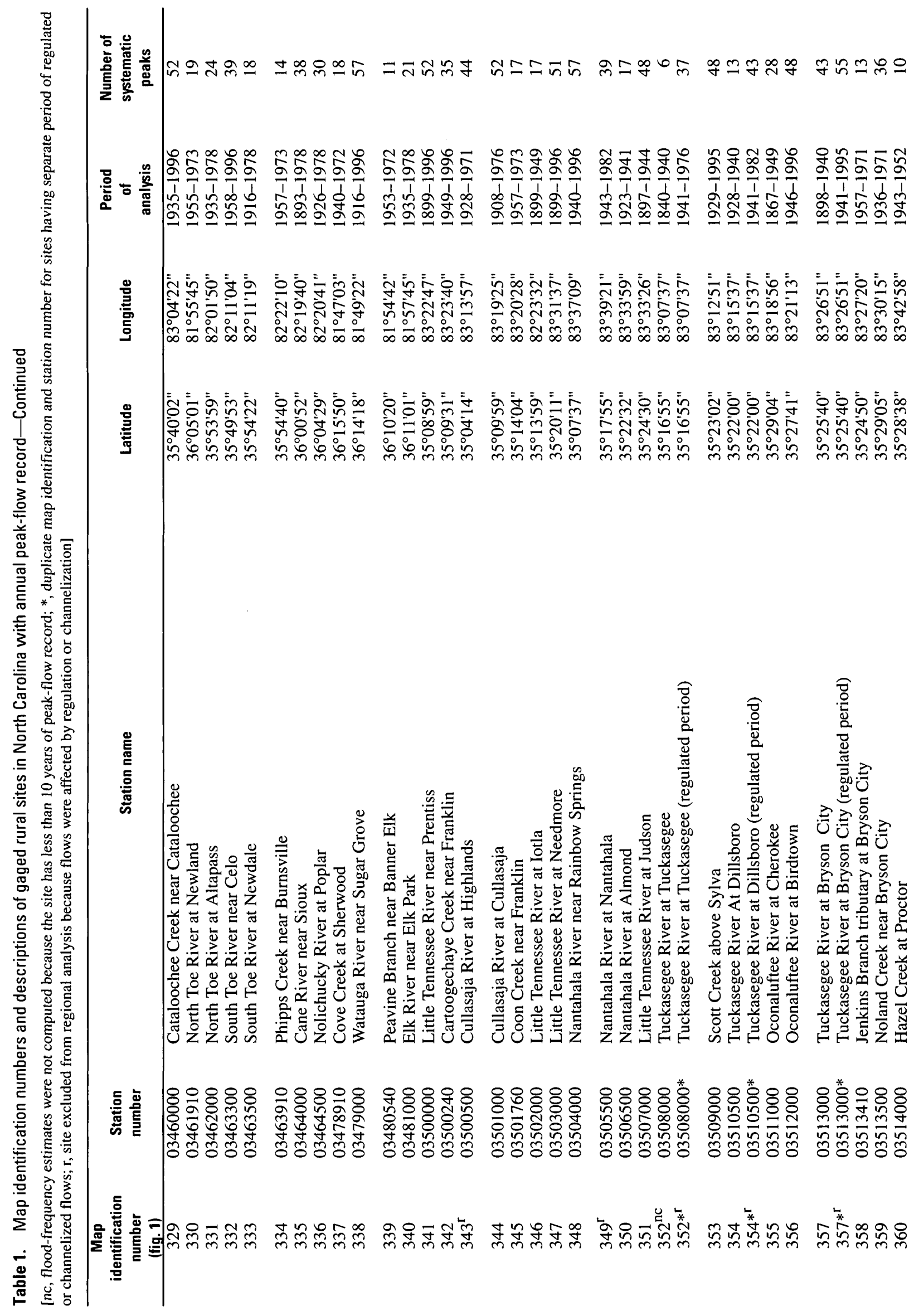




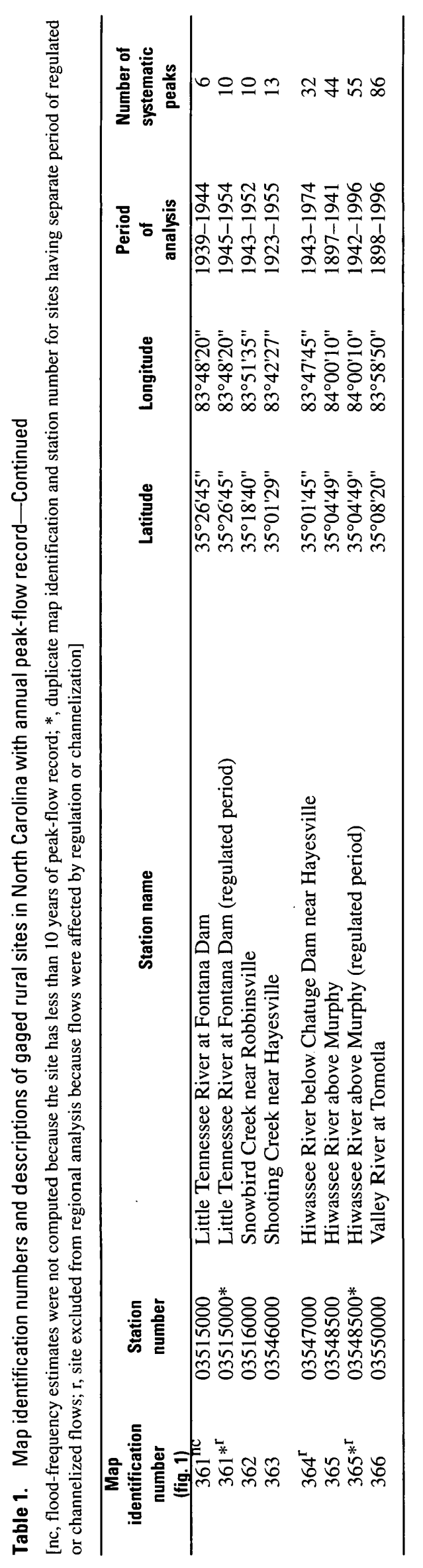




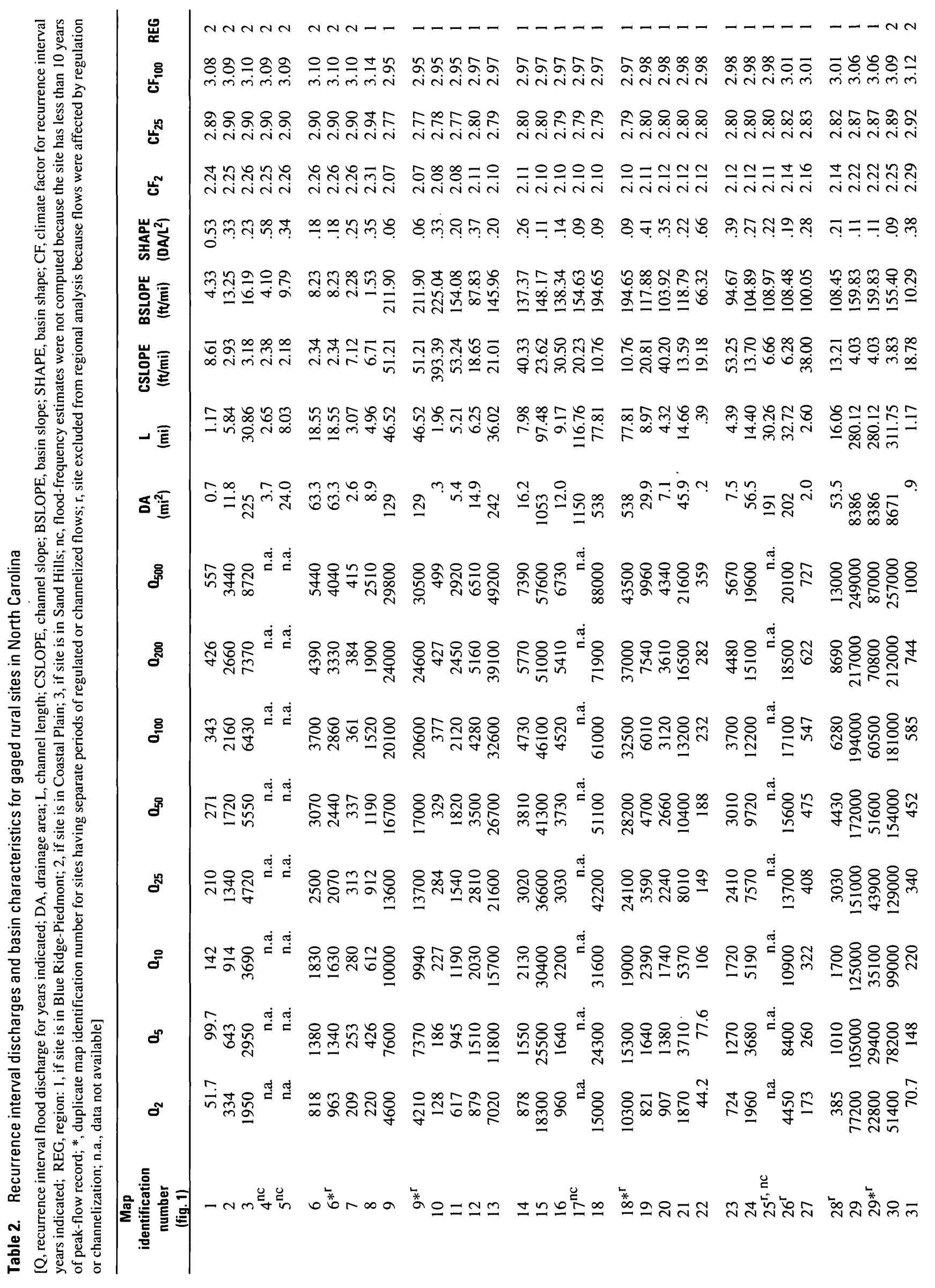




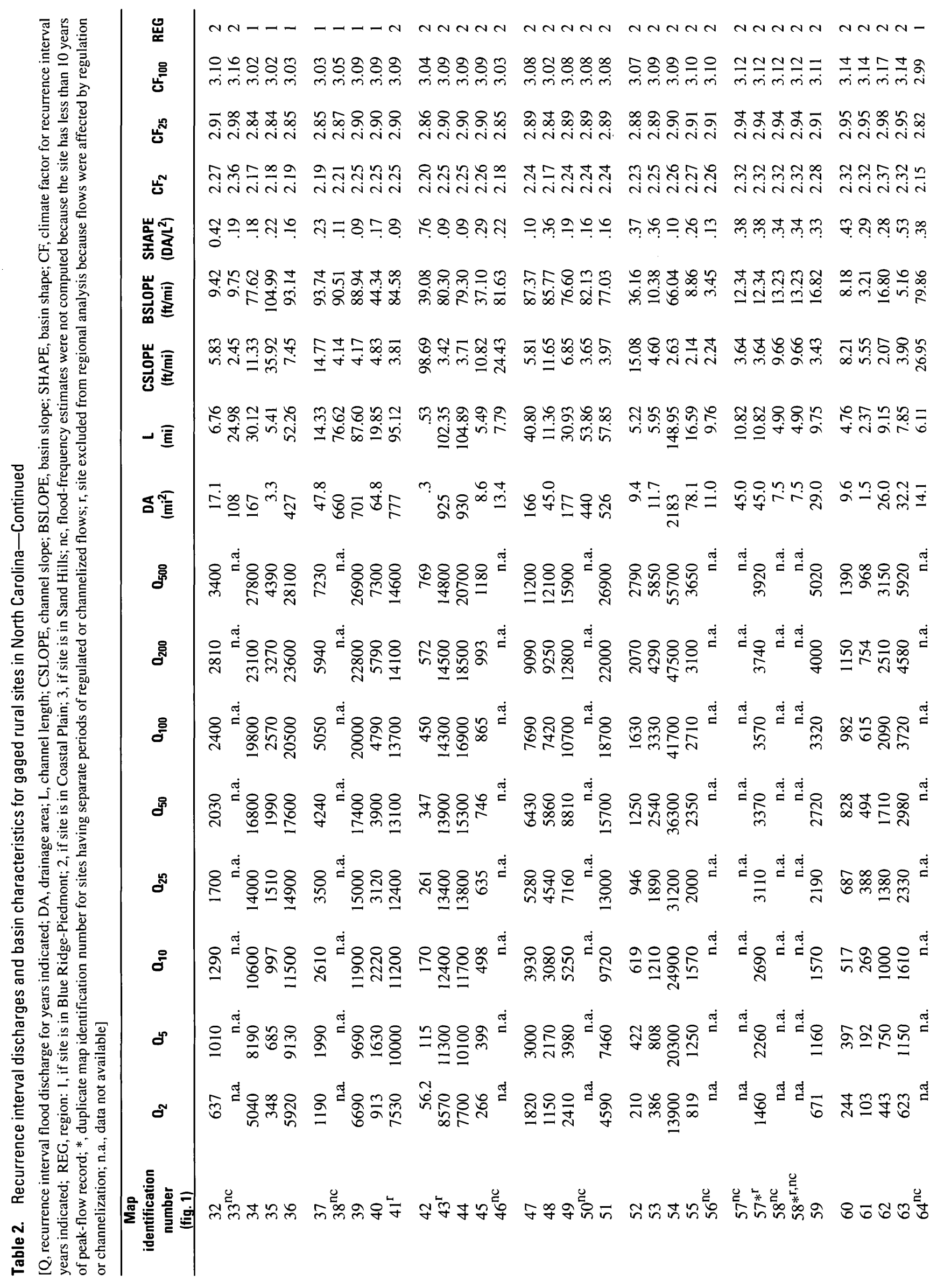




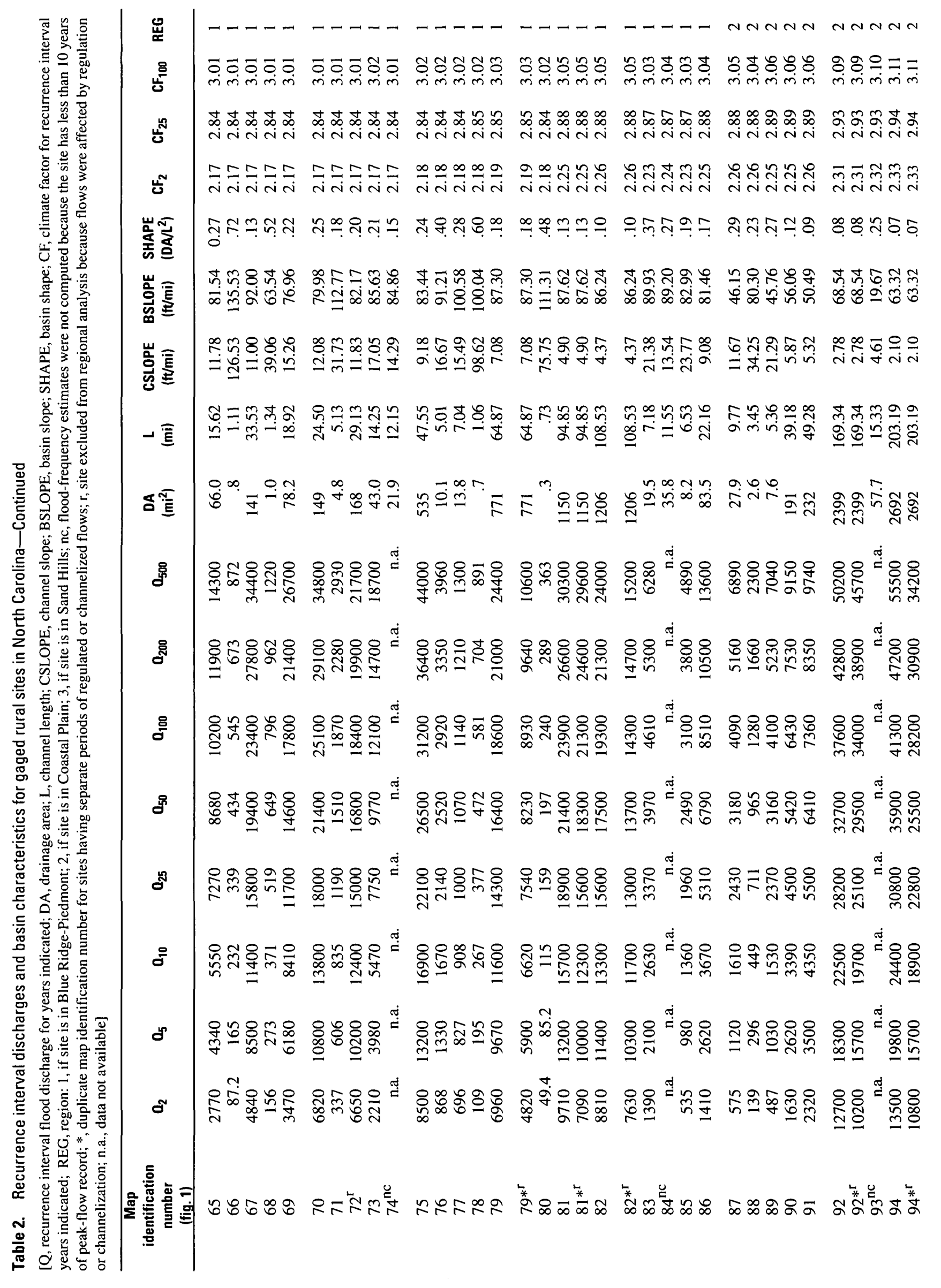

Tables $\quad 33$ 


\begin{tabular}{|c|c|c|c|c|c|c|c|c|}
\hline 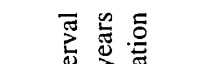 & 峞 & NNNNN & $N N N N N$ & $N N N N N$ & $N N N N N$ & NNNNN & --7 & -ーーー \\
\hline 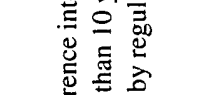 & 题 & 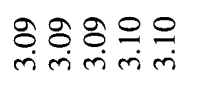 & $\begin{array}{l}8 \\
\dot{m}\end{array}$ & 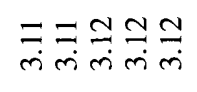 & 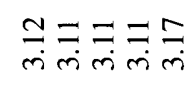 & $\stackrel{m}{m} \underset{m}{m}=$ & 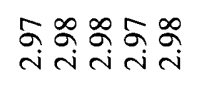 & 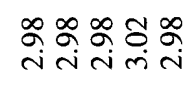 \\
\hline 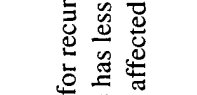 & บี & 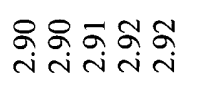 & 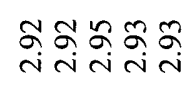 & 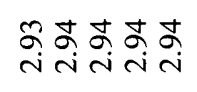 & 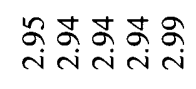 & 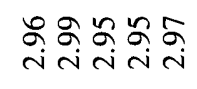 & 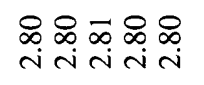 & 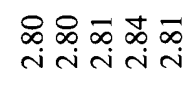 \\
\hline 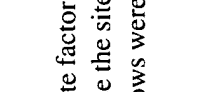 & 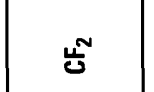 & 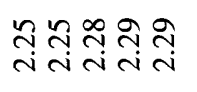 & 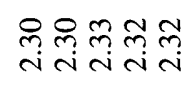 & 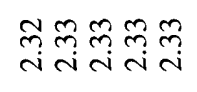 & 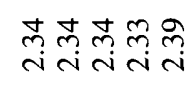 & 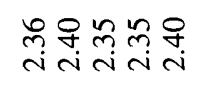 & 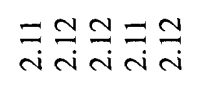 & $\underset{i}{i} \underset{i}{i} \underset{i}{i} \frac{m}{i}$ \\
\hline 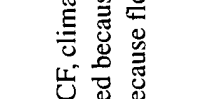 & 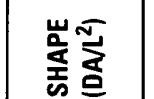 & 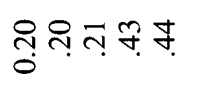 & 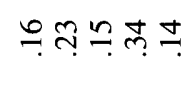 & শ̣̣ & 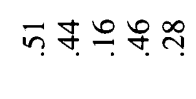 & ํㅠㅠ. & 웅으 구 & 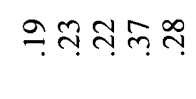 \\
\hline 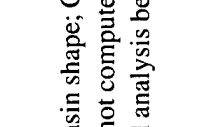 & 嵩离 & 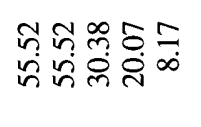 & 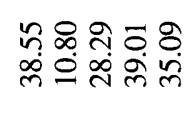 & 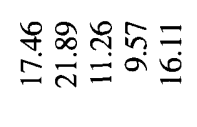 & 品 & 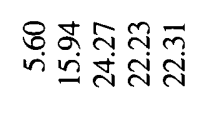 & 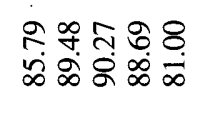 & 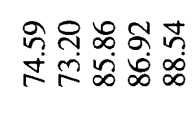 \\
\hline 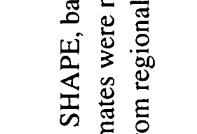 & 嵩言 & 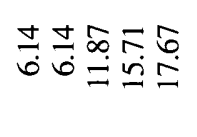 & 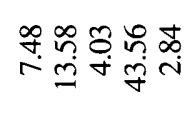 & 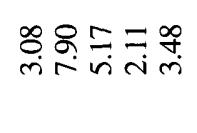 & 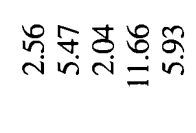 & הి & 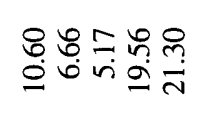 & 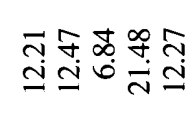 \\
\hline 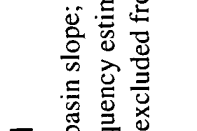 & - $\overline{\bar{E}}$ & 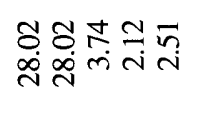 & 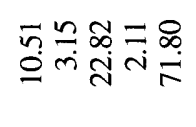 & 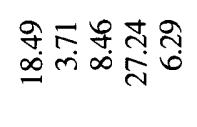 & 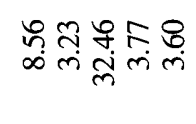 & 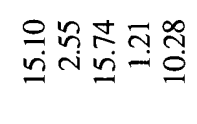 & 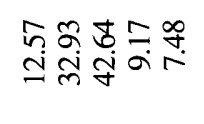 & 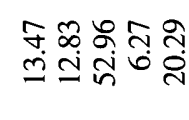 \\
\hline 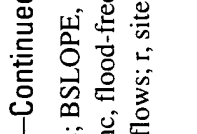 & $\Phi \bar{\Phi}$ & $\underline{\sigma}_{\underline{\sigma}} \stackrel{\infty}{i} \vec{i} \stackrel{0}{i}$ & 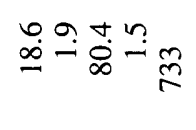 & 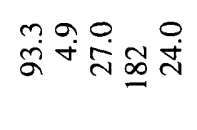 & 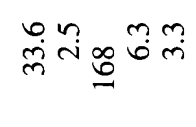 & 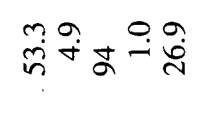 & 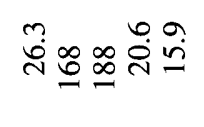 & ஜூં \\
\hline 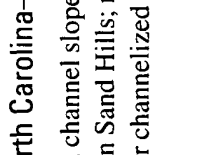 & 总 & 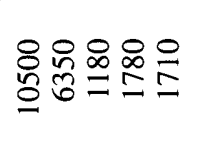 & 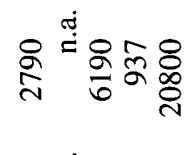 & 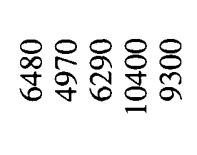 & 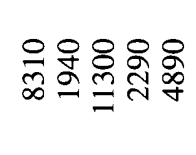 & 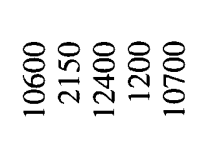 & 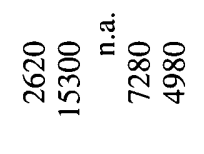 & 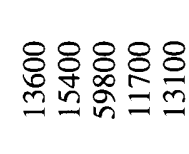 \\
\hline 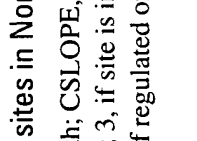 & క్సి & 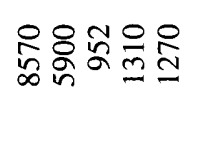 & 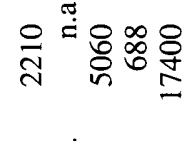 & 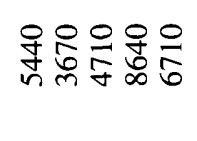 & 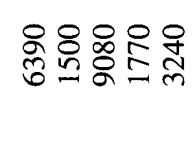 & 웅융 & 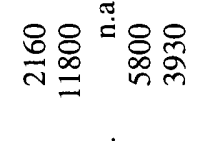 & 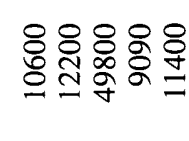 \\
\hline 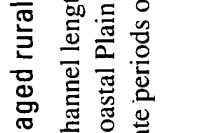 & 8 & 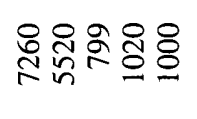 & 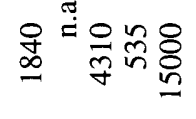 & 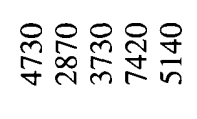 & 옴웜웜윰유 & 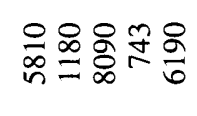 & 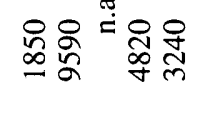 & 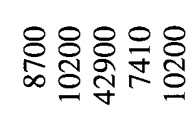 \\
\hline 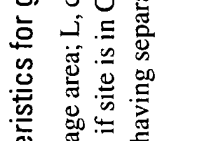 & 오 & 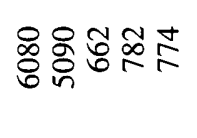 & 음 & 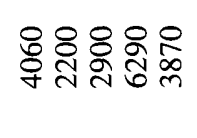 & 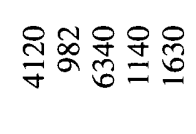 & 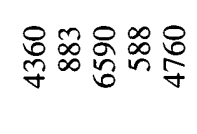 & 윰융 & 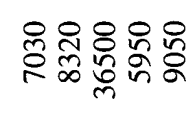 \\
\hline 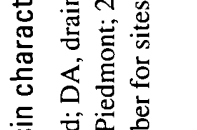 & $\sigma^{2}$ & 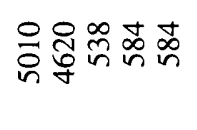 & త্ & 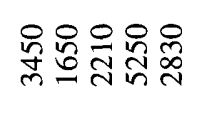 & స్లిNㅀㅇㅛ & 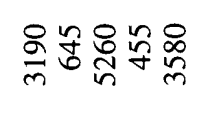 & \&্ల్ర & 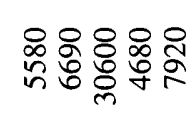 \\
\hline 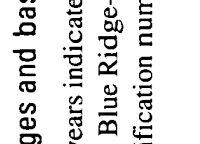 & 0 & 용్ㅇ్ㅀㅇㅛ & 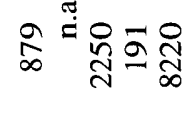 & 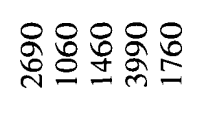 & స్సి & 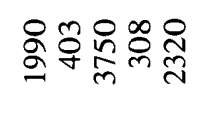 & 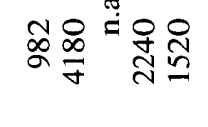 & 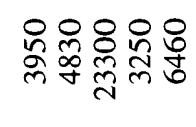 \\
\hline 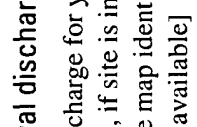 & ø & 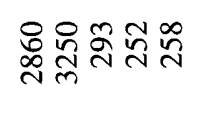 & 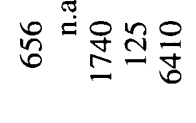 & $\frac{n}{N} \approx \delta 8$ & 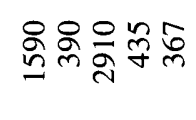 & 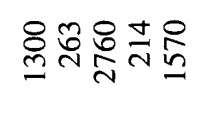 & 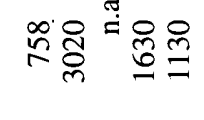 & 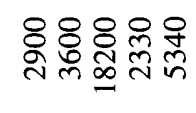 \\
\hline 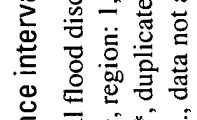 & $\sigma^{N}$ & 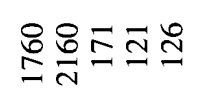 & ফ্লల & 웜윰흄음 & 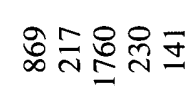 & 잉조용ㅇㅇㅇ & 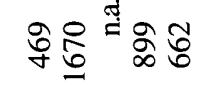 & 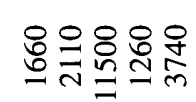 \\
\hline 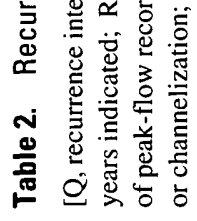 & 兽 & 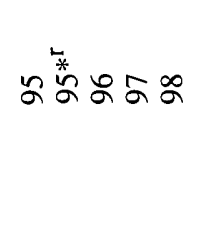 & & む气 & g응 & 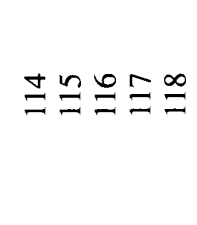 & $\varrho \stackrel{\mathscr{E}}{\Xi} \cong \cong$ & $\stackrel{\Xi}{\beth}$ \\
\hline
\end{tabular}




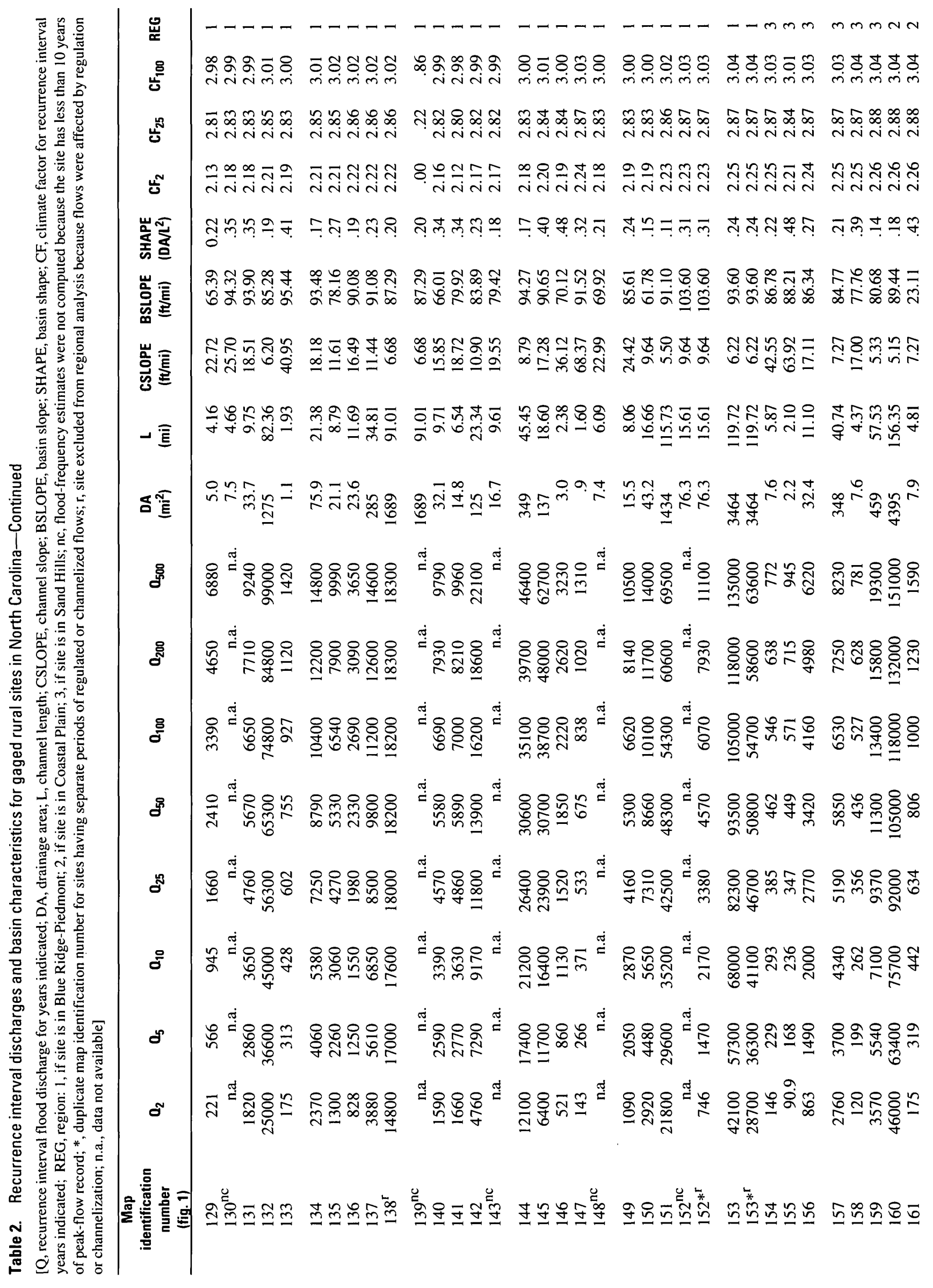




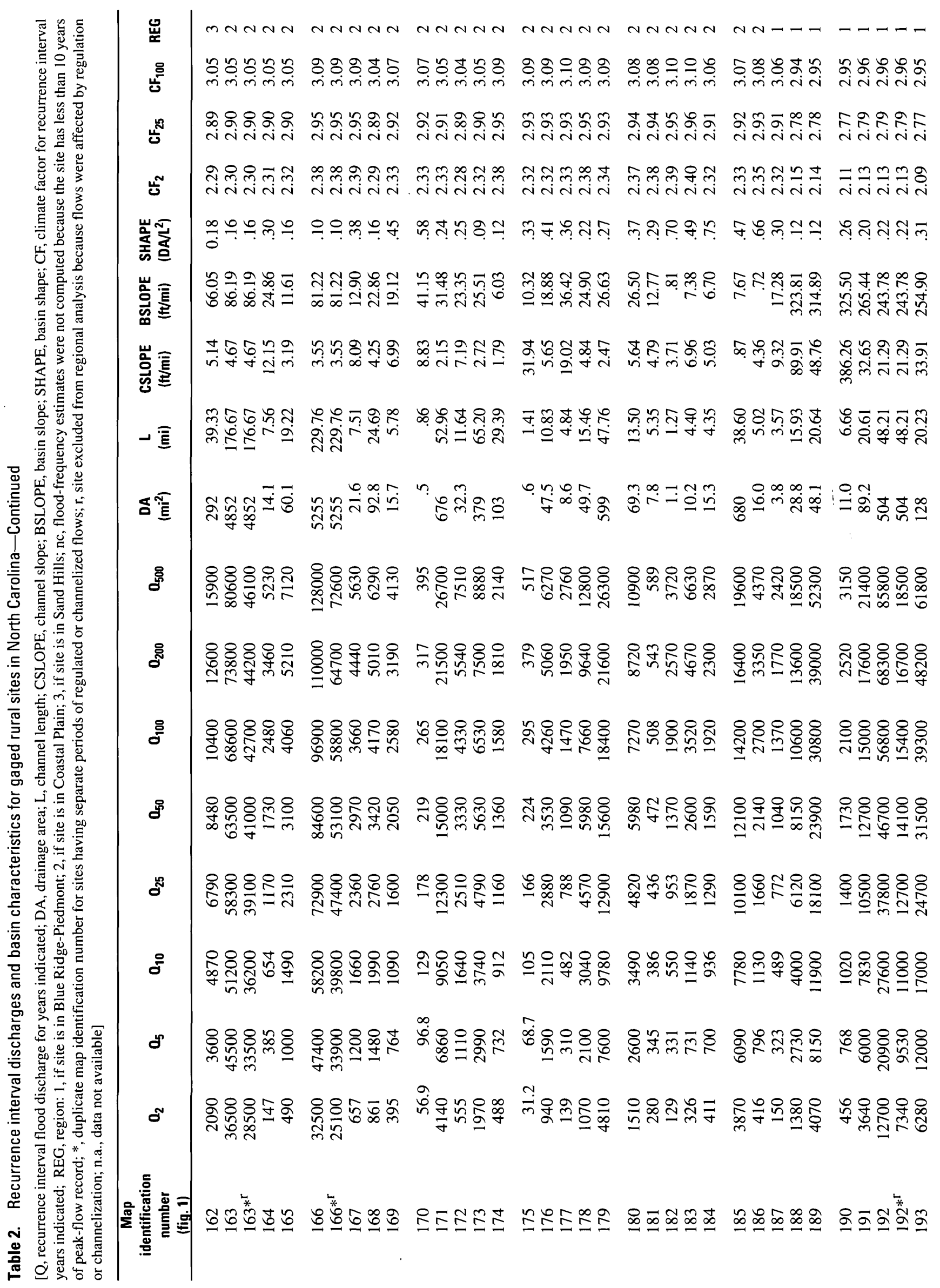




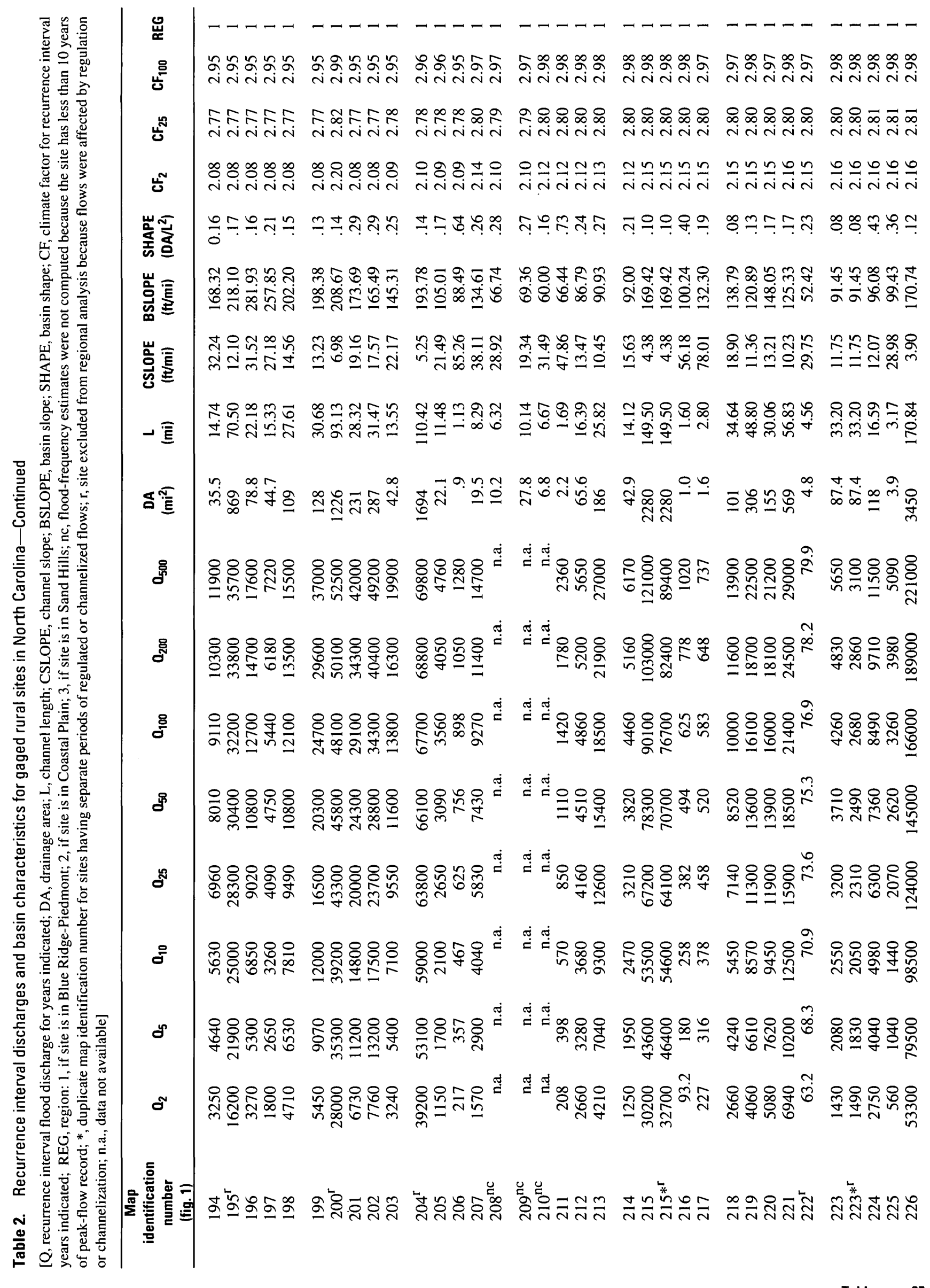

Tables $\quad 37$ 


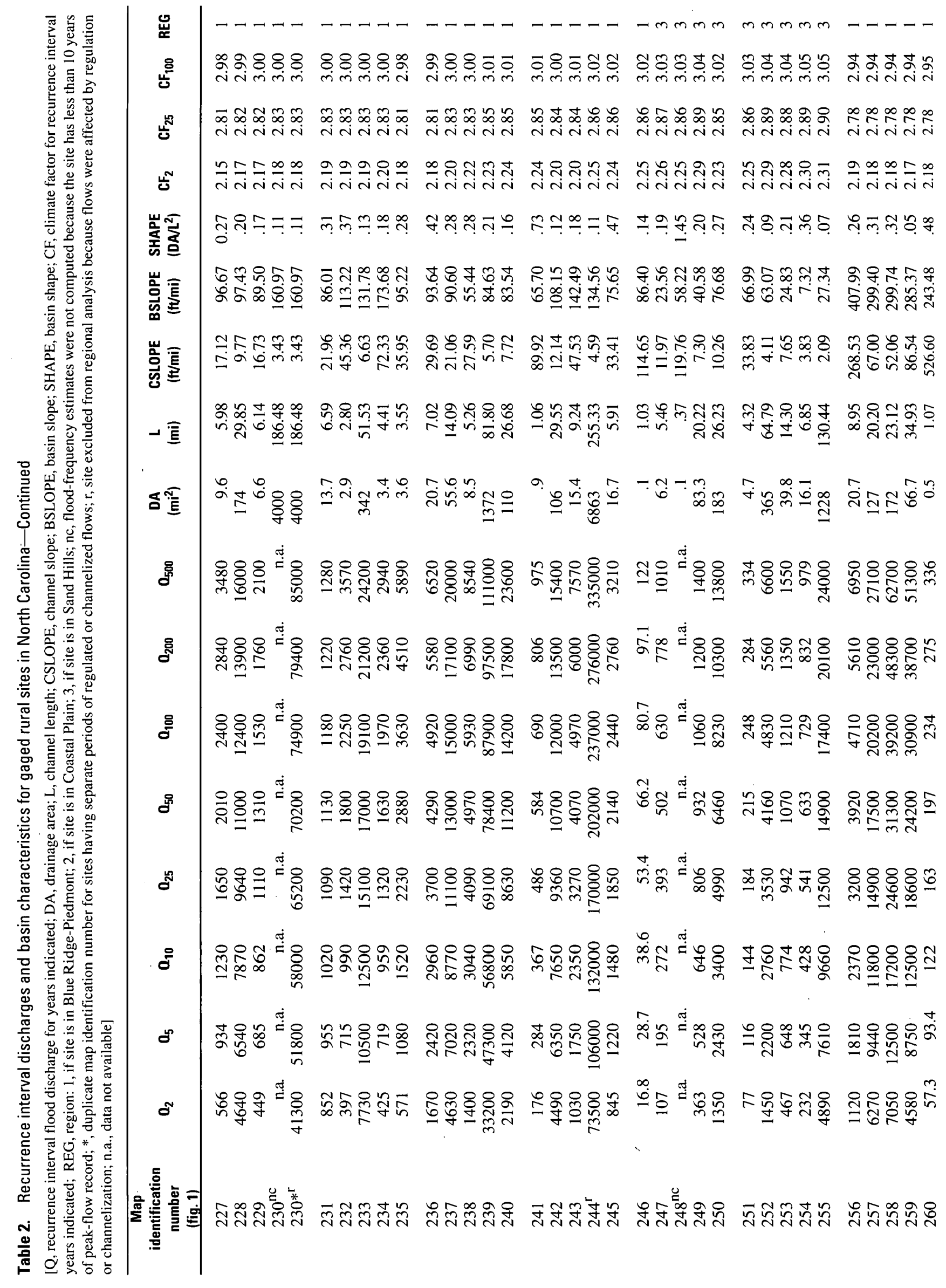




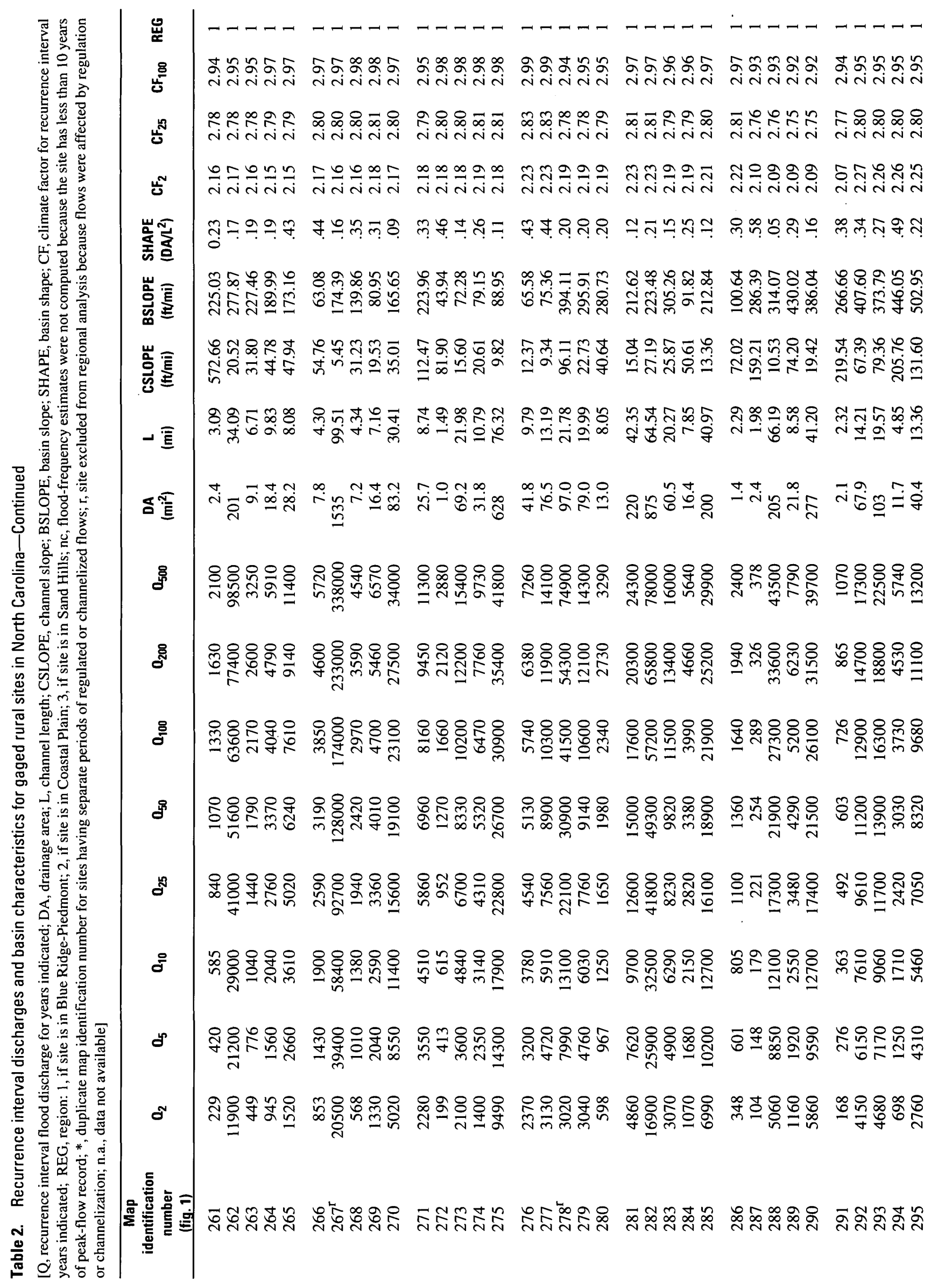




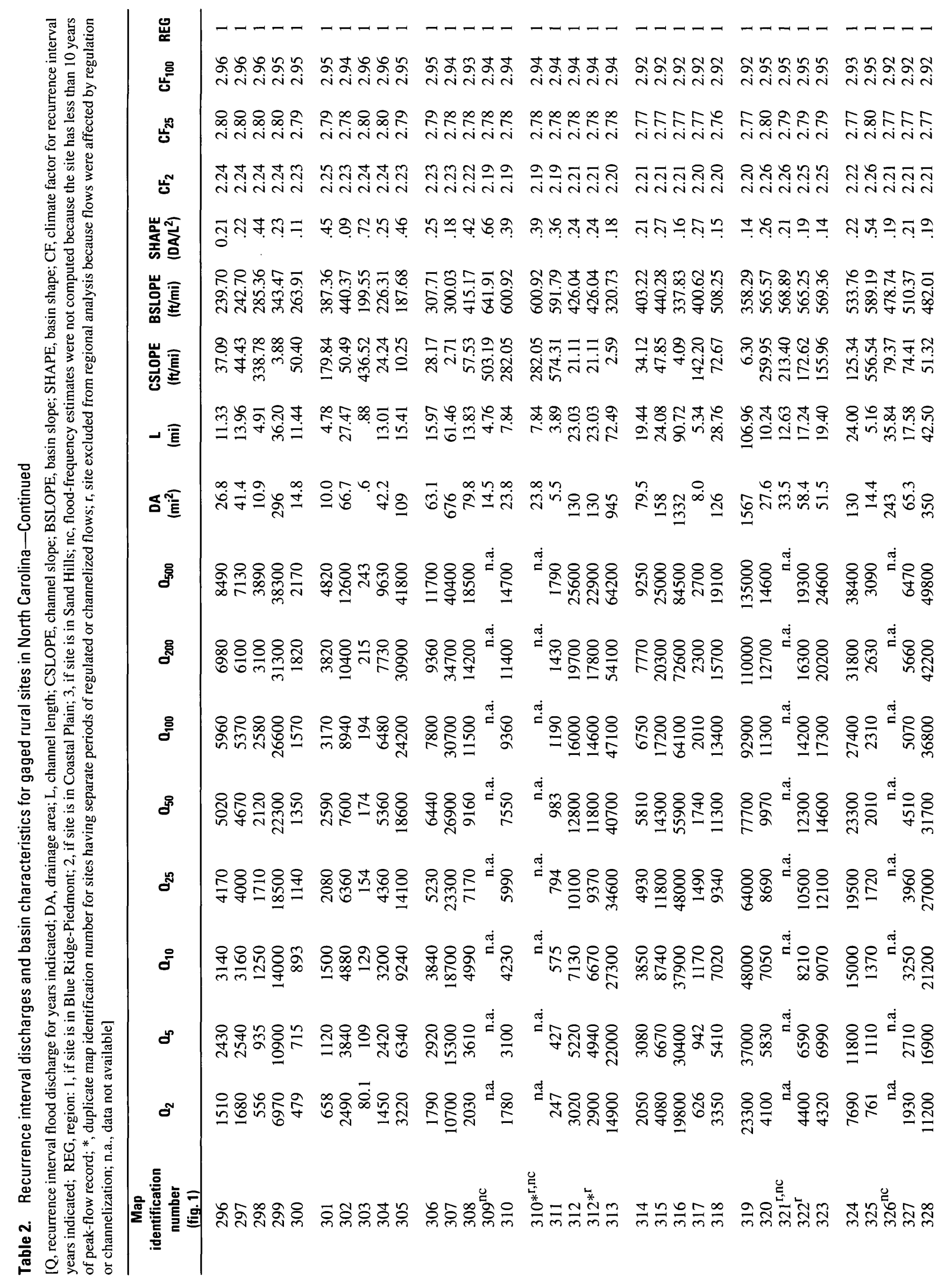




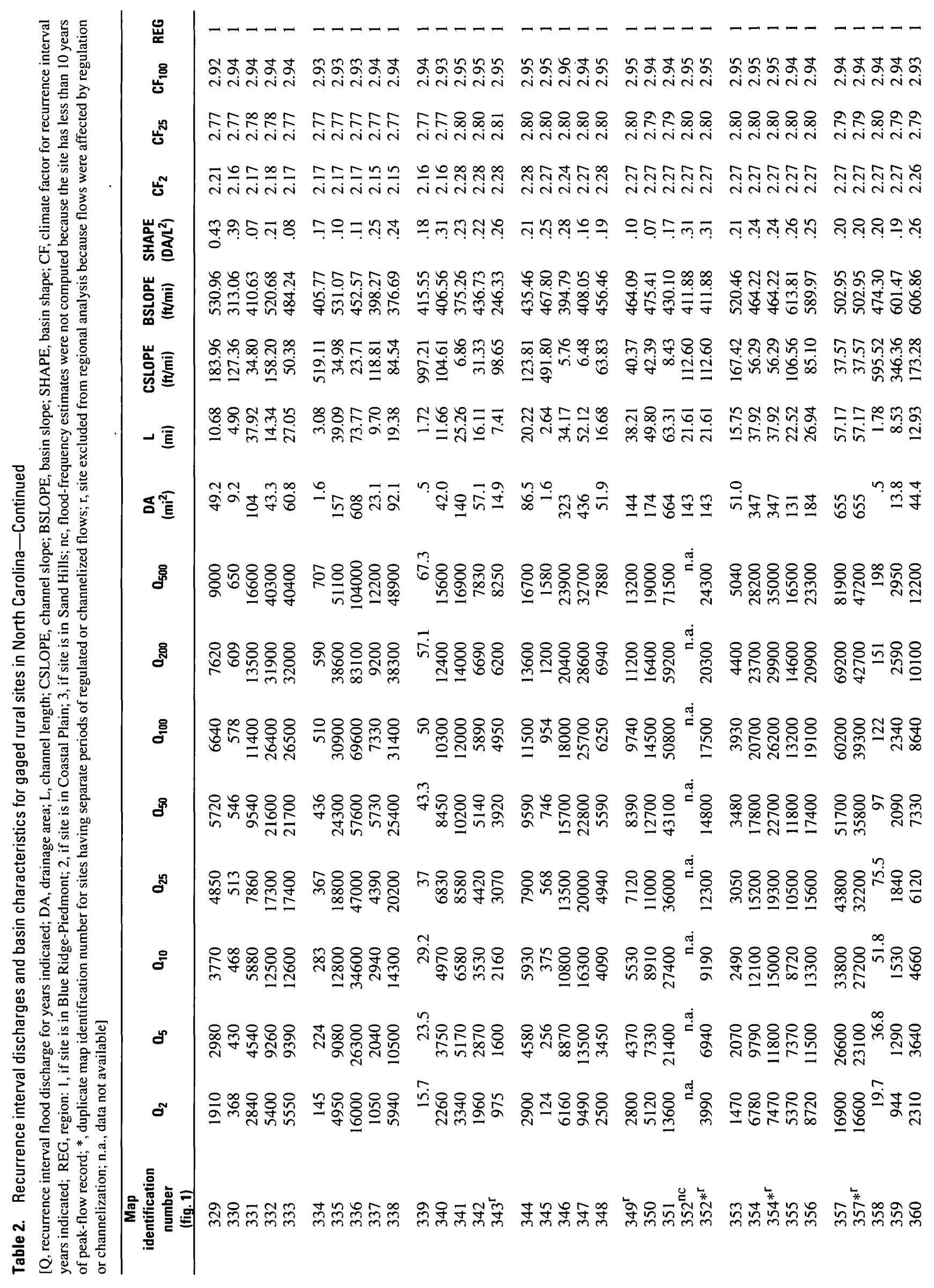




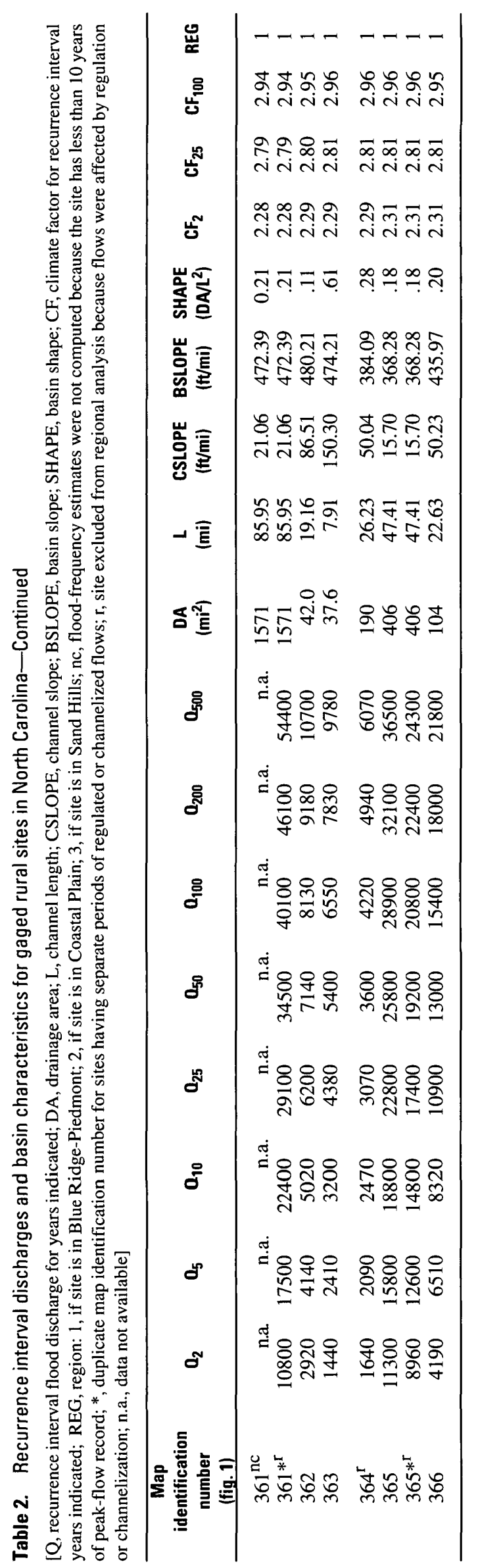




\section{APPENDIX}

The value of the mean square error $\left(M S E_{s}\right)$ at a specific site can be estimated as follows: Denote the column vector of $n$ logarithms of observed peakdischarge characteristics at $n$ sites in a region by $Y$. For example,

$$
Y=\left[\begin{array}{c}
\log Q_{50,1} \\
\log Q_{50,2} \\
" " \\
\log Q_{50, n}
\end{array}\right]
$$

in which, $Q_{50, i}$, represents the observed 50-year peak at the $i$ th gaging station in the region. Further, let $X$ represent a ( $n$ by $p$ ) matrix of $p$-1 basin characteristics augmented by a column of ones at $n$ gaging stations and $B$ represent a column vector of $p$ regression coefficients.

For example,

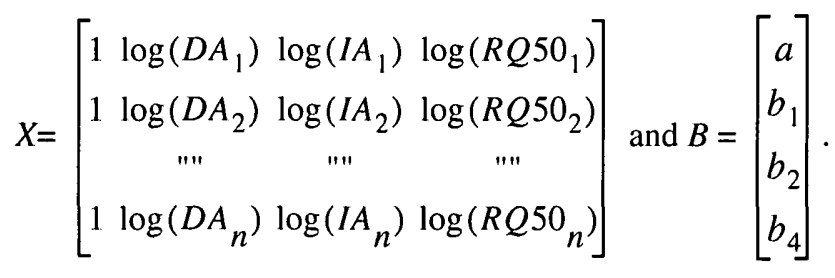

The linear model can be written as

$$
Y=X B \text {. }
$$

The mean square sampling error, $M S E_{\mathrm{s}, 0}$, for an ungaged site with basin characteristics given by the row vector $x_{0}=\left[1 \log \left(D A_{0}\right) \log \left(I A_{0}\right) \log \left(R Q 50_{0}\right)\right]$, for example, is calculated as

$$
M S E_{\mathrm{s}, 0}=x_{0}\left\{X^{T} \Lambda^{-1} X\right\}^{-1} x_{0}{ }^{T}
$$

in which $\Lambda$ is the ( $n$ by $n$ ) covariance matrix associated with $Y$. The diagonal elements of $\Lambda$ are model error variance, $\gamma^{2}$, plus the time-sampling error for each site $i(i=1,2,3, \ldots n)$, which is estimated as a function of a regional estimate of the standard deviation of annual peaks at site $i$, the recurrence interval of the dependent variable and the number of years of record at site $i$. The off-diagonal elements of $\Lambda$ are the sample covariance of the estimated $t$-year peaks at sites $i$ and $j$. These offdiagonal elements are estimated as a function of a regional estimate of the standard deviation of annual peaks at sites $i$ and $j$, the recurrence interval of the dependent variable and the number of concurrent years of record at sites $i$ and $j$ (Tasker and Stedinger, 1989). The ( $p$ by $p$ ) matrix $\left\{X^{T} \Lambda^{-1} X\right\}^{-1}$ for each equation is given in Appendix table 1 . The mean square error of a prediction, in log (base 10) units, at specific ungaged sites can be estimated as

$$
M S E_{p, 0}=\left(\gamma^{2}+M S E_{s, 0}\right)
$$

The standard error of a prediction, $S E_{\text {prediction, in }}$ percent, can be calculated as

$$
S E_{\text {prediction }}=100\left\{e^{5.302 \times(M S E p, 0)}-1\right\}^{0.5}
$$


Appendix Table 1. Matrix $\left\{X^{T} \Lambda^{-1} X\right\}^{-1}$ for the equations in table 5 (p. 11)

[These matrices can be used to compute the standard error of prediction and prediction intervals as explained in the text. Numbers are given in scientific notation, for example, $\left.0.43958 \mathrm{E}-01=0.43958 \times 10^{-1}=0.043958\right]$

\begin{tabular}{|c|c|c|c|c|c|}
\hline \multicolumn{6}{|c|}{ Hydrologic area } \\
\hline \multicolumn{2}{|c|}{ Blue Ridge-Piedmont } & \multicolumn{2}{|c|}{ Coastal Plain } & \multicolumn{2}{|c|}{ Sand Hills } \\
\hline \multicolumn{6}{|c|}{ 2-year recurrence interval } \\
\hline $0.14072 \mathrm{E}-02$ & $-0.49612 \mathrm{E}-03$ & $0.31893 \mathrm{E}-02$ & $-0.98276 \mathrm{E}-03$ & $0.10200 \mathrm{E}-01$ & $-0.44648 \mathrm{E}-02$ \\
\hline$-0.49612 \mathrm{E}-03$ & $0.24350 \mathrm{E}-03$ & $-0.98276 \mathrm{E}-03$ & $0.43777 \mathrm{E}-03$ & $-0.44648 \mathrm{E}-02$ & $0.25105 \mathrm{E}-02$ \\
\hline \multicolumn{6}{|c|}{ 5-year recurrence interval } \\
\hline $0.16431 \mathrm{E}-02$ & $-0.55517 \mathrm{E}-03$ & $0.37147 \mathrm{E}-02$ & $-0.10840 \mathrm{E}-02$ & $0.12971 \mathrm{E}-01$ & $-0.56042 \mathrm{E}-02$ \\
\hline$-0.55517 \mathrm{E}-03$ & $0.26322 \mathrm{E}-03$ & $-0.10840 \mathrm{E}-02$ & $0.45031 \mathrm{E}-03$ & $-0.56042 \mathrm{E}-02$ & $0.31270 \mathrm{E}-02$ \\
\hline \multicolumn{6}{|c|}{ 10-year recurrence interval } \\
\hline $0.18985 \mathrm{E}-02$ & $-0.62424 \mathrm{E}-03$ & $0.43917 \mathrm{E}-02$ & $-0.12495 \mathrm{E}-02$ & $0.15456 \mathrm{E}-01$ & $-0.65943 \mathrm{E}-02$ \\
\hline$-0.62424 \mathrm{E}-03$ & $0.28912 \mathrm{E}-03$ & $-0.12495 \mathrm{E}-02$ & $0.50084 \mathrm{E}-03$ & $-0.65943 \mathrm{E}-02$ & $0.36522 \mathrm{E}-02$ \\
\hline \multicolumn{6}{|c|}{ 25-year recurrence interval } \\
\hline $0.22833 \mathrm{E}-02$ & $-0.73140 \mathrm{E}-03$ & $0.54496 \mathrm{E}-02$ & $-0.15204 \mathrm{E}-02$ & $0.19118 \mathrm{E}-01$ & $-0.80470 \mathrm{E}-02$ \\
\hline$-0.73140 \mathrm{E}-03$ & $0.33094 \mathrm{E}-03$ & $-0.15204 \mathrm{E}-02$ & $0.59196 \mathrm{E}-03$ & $-0.80470 \mathrm{E}-02$ & $0.44209 \mathrm{E}-02$ \\
\hline \multicolumn{6}{|c|}{ 50-year recurrence interval } \\
\hline $0.25999 \mathrm{E}-02$ & $-0.82124 \mathrm{E}-03$ & $0.63333 \mathrm{E}-02$ & $-0.17517 \mathrm{E}-02$ & $0.22136 \mathrm{E}-01$ & $-0.92451 \mathrm{E}-02$ \\
\hline$-0.82124 \mathrm{E}-03$ & $0.36687 \mathrm{E}-03$ & $-0.17517 \mathrm{E}-02$ & $0.67303 \mathrm{E}-03$ & $-0.92451 \mathrm{E}-02$ & $0.50554 \mathrm{E}-02$ \\
\hline \multicolumn{6}{|c|}{ 100-year recurrence interval } \\
\hline $0.29342 \mathrm{E}-02$ & $-0.91725 \mathrm{E}-03$ & $0.72726 \mathrm{E}-02$ & $-0.20005 E-02$ & $0.25348 \mathrm{E}-01$ & $-0.10523 \mathrm{E}-01$ \\
\hline$-0.91725 \mathrm{E}-03$ & $0.40581 \mathrm{E}-03$ & $-0.20005 \mathrm{E}-02$ & $0.76200 \mathrm{E}-03$ & $-0.10523 \mathrm{E}-01$ & $0.57330 \mathrm{E}-02$ \\
\hline \multicolumn{6}{|c|}{ 200-year recurrence interval } \\
\hline $0.32839 \mathrm{E}-02$ & $-0.10186 \mathrm{E}-02$ & $0.82596 \mathrm{E}-02$ & $-0.22640 \mathrm{E}-02$ & $0.28740 \mathrm{E}-01$ & $-0.11875 \mathrm{E}-01$ \\
\hline$-0.10186 \mathrm{E}-02$ & $0.44737 \mathrm{E}-03$ & $-0.22640 \mathrm{E}-02$ & $0.85763 \mathrm{E}-03$ & $-0.11875 \mathrm{E}-01$ & $0.64516 \mathrm{E}-02$ \\
\hline \multicolumn{6}{|c|}{ 500-year recurrence interval } \\
\hline $0.37671 \mathrm{E}-02$ & $-0.11600 \mathrm{E}-02$ & $0.96272 \mathrm{E}-02$ & $-0.26319 \mathrm{E}-02$ & $0.33482 \mathrm{E}-01$ & $-0.13772 \mathrm{E}-01$ \\
\hline$-0.11600 \mathrm{E}-02$ & $0.50586 \mathrm{E}-03$ & $-0.26319 \mathrm{E}-02$ & $0.99272 \mathrm{E}-03$ & $-0.13772 \mathrm{E}-01$ & $0.74616 \mathrm{E}-02$ \\
\hline
\end{tabular}




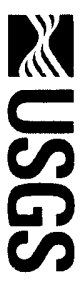

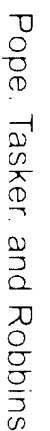

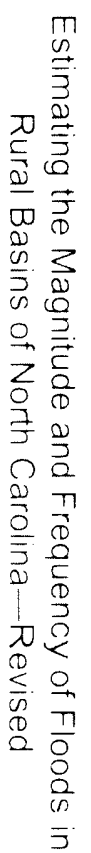

(1) Printed on recycled paper 